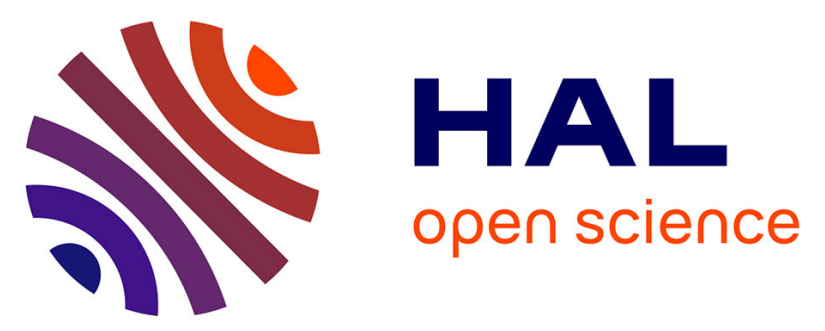

\title{
Effective Catalytic Delignification and Fractionation of Lignocellulosic Biomass in Water over Zn3V2O8 Mixed Oxide
}

Khadija Khallouk, Abderrahim Solhy, Abdelhak Kherbeche, Eric Dubreucq, Lamfeddal Kouisni, Abdellatif Barakat

\section{To cite this version:}

Khadija Khallouk, Abderrahim Solhy, Abdelhak Kherbeche, Eric Dubreucq, Lamfeddal Kouisni, et al.. Effective Catalytic Delignification and Fractionation of Lignocellulosic Biomass in Water over Zn3V2O8 Mixed Oxide. ACS Omega, 2020, 5 (1), pp.304-316. 10.1021/acsomega.9b02159 . hal02619329

\section{HAL Id: hal-02619329 \\ https://hal.inrae.fr/hal-02619329}

Submitted on 25 May 2020

HAL is a multi-disciplinary open access archive for the deposit and dissemination of scientific research documents, whether they are published or not. The documents may come from teaching and research institutions in France or abroad, or from public or private research centers.
L'archive ouverte pluridisciplinaire HAL, est destinée au dépôt et à la diffusion de documents scientifiques de niveau recherche, publiés ou non, émanant des établissements d'enseignement et de recherche français ou étrangers, des laboratoires publics ou privés.

\section{(c) (1) $\$$}

Distributed under a Creative Commons Attribution - NonCommerciall 4.0 International 


\title{
Effective Catalytic Delignification and Fractionation of Lignocellulosic Biomass in Water over $\mathrm{Zn}_{3} \mathrm{~V}_{2} \mathrm{O}_{8}$ Mixed Oxide
}

\author{
Khadija Khallouk, ${ }^{\dagger, \ddagger \S}$ Abderrahim Solhy, ${ }^{\S}$ Abdelhak Kherbeche, ${ }^{\ddagger}$ Eric Dubreucq, ${ }^{\dagger}$ Lamfeddal Kouisni, ${ }^{\S}$ \\ and Abdellatif Barakat $*, \dagger,{ }^{\circ}$
}

\author{
${ }^{\dagger}$ IATE, Montpellier SupAgro, INRAE, Université de Montpellier, 2, Place Pierre Viala, 34060 Montpelier, France \\ ${ }^{\ddagger}$ LCME, EST, Université Sidi Mohammed Ben Abdellah, 30000 Fès, Maroc \\ ${ }^{\S}$ Mohammed VI Polytechnic University (UM6P), Hay Moulay Rachid, 43150 Ben Guerir, Maroc
}

Supporting Information

\begin{abstract}
The conversion of poplar wood biomass to highly value-added chemicals and molecular building blocks was achieved by using the dispersed mixed oxide $\mathrm{Zn}_{3} \mathrm{~V}_{2} \mathrm{O}_{8}$ (ZVO) in water under $100 \mathrm{kPa}$ of $10 \% \mathrm{O}_{2} / \mathrm{N}_{2}$ at 160 , 180 , and $200{ }^{\circ} \mathrm{C}$ for $4 \mathrm{~h}$. This nanostructured mixed oxide was prepared via the precipitation process and then characterized by several techniques. The results showed that this mixed oxide has interesting catalytic properties and is a versatile catalyst for biomass delignification and lignin and hemicellulose depolymerization. ZVO exhibited high activity on poplar biomass delignification and fractionation (degree of delignification $>97 \%$ ) and lignin and holocellulose conversion with high yield into aromatic and furan compounds $(80 \mathrm{mg} / \mathrm{g}$ initial wood at $200{ }^{\circ} \mathrm{C}$ ), with high selectivities for 5-hydroxymethylfurfural (HMF) (25 $\mathrm{mg} / \mathrm{g}$ of initial wood), vanillin, and syringaldehyde.
\end{abstract}

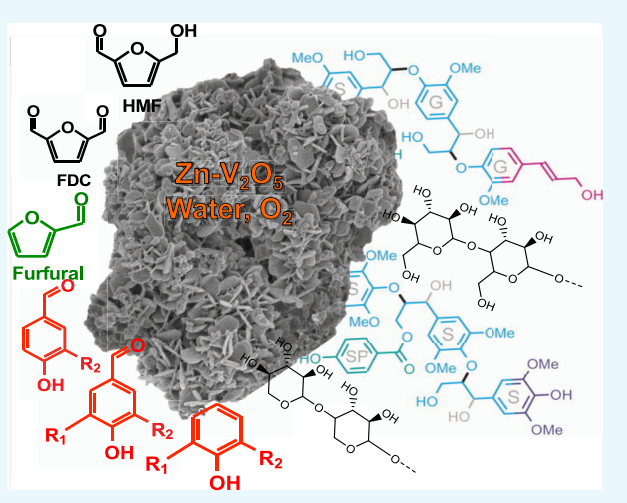

\section{INTRODUCTION}

Lignocellulosic biomass utilization as a source of clean energy and chemicals has attracted attention in recent years in the context of the fossil fuel energy crisis and the clean energy drive. $^{1,2}$ Lignocellulosic biomass consists of cellulose, hemicelluloses, and lignin fractions (Scheme 1), which quantitatively and qualitatively vary according to the plant material. Hemicelluloses serve as a connection between lignin and cellulose fibers and give the whole cellulose-hemicelluloseslignin network more rigidity. ${ }^{3,4}$ Unlike cellulose and hemicelluloses, lignin is a cross-linked hydrophobic polymer ${ }^{5}$ that is insoluble in most solvents and fairly resistant to anaerobic degradation. Hence, a pretreatment of lignocellulosic materials to dissolve the lignin structure (delignification) and cleave the chains seems to be necessary before enzymatic and chemicalthermal processes to avail important chemicals from biomass. Delignification of the lignocellulosic biomass has been investigated in many studies, for example, recently in the production of Kraft pulps, lactic acid, and bioethanol. ${ }^{6-9}$ The obtained fibrous material is composed mainly of cellulose (80$90 \%)$, hemicelluloses (5-15\%), and lignin (2.5-4\%). The industrial pulping technologies deal mainly with sulfur-based reagents, while the bleaching technologies are mainly chlorinebased. Both have a negative impact on the environment. A disadvantage of these pretreatment methods is that, for example, during the subsequent anaerobic and chemical degradation, hydrogen sulfide is formed, lowering the quality of the produced biomolecules. Recently, molecular oxygen delignification in alkaline media has been widely reported as a potential technique for lignin degradation due to its low process cost and its energy efficiency. ${ }^{6,7,10,11}$ In this process, effects of sodium hydroxide $(\mathrm{NaOH})$, hydrogen peroxide $\left(\mathrm{H}_{2} \mathrm{O}_{2}\right)$, oxygen pressure, and temperature on decomposing lignin have been reported. A review of the oxygen delignification literature indicates that a co-oxidant and/or catalyst is most frequently used in the delignification and pretreatments of lignocellulosic biomass. ${ }^{6,10,12,13}$ An alternative means of enhancing the degree of delignification in an oxygen delignification process is to develop novel catalysts that could increase lignin degradation by oxidation in water without adding large amounts of chemicals. The use of recyclable bimetallic dispersed oxides for the fragmentation of lignocellulosic biomass in water $(\mathrm{pH}=7)$ limits problems derived from equipment corrosion owing to the mild $\mathrm{pH}$ of the reaction media and also reduces the operational costs since no further neutralization is needed.

Transition-metal vanadates are a significant category of mixed oxides that have received lively interest, notably for their big potential for applications in photocatalysis, materials for electrochemical energy storage, superparamagnetic compounds, and high-performance microwave devices. ${ }^{14-18}$ Various mixed oxides of this family have been synthesized. Here, we quote mainly zinc vanadate $\left(\mathrm{Zn}_{3} \mathrm{~V}_{2} \mathrm{O}_{8}(\mathrm{ZVO})\right)$, which will be this paper's subject. $\mathrm{ZVO}$ has attracted

Received: August 22, 2019

Accepted: December 6, 2019

Published: December 31, 2019 
Scheme 1. Chemical Structure and Reaction Pathways of the Major Products Obtained from the Catalytic Fragmentation of a Lignocellulosic Matrix in Water over a $\mathrm{Zn}_{3} \mathrm{~V}_{2} \mathrm{O}_{8}$ (ZVO) Catalyst

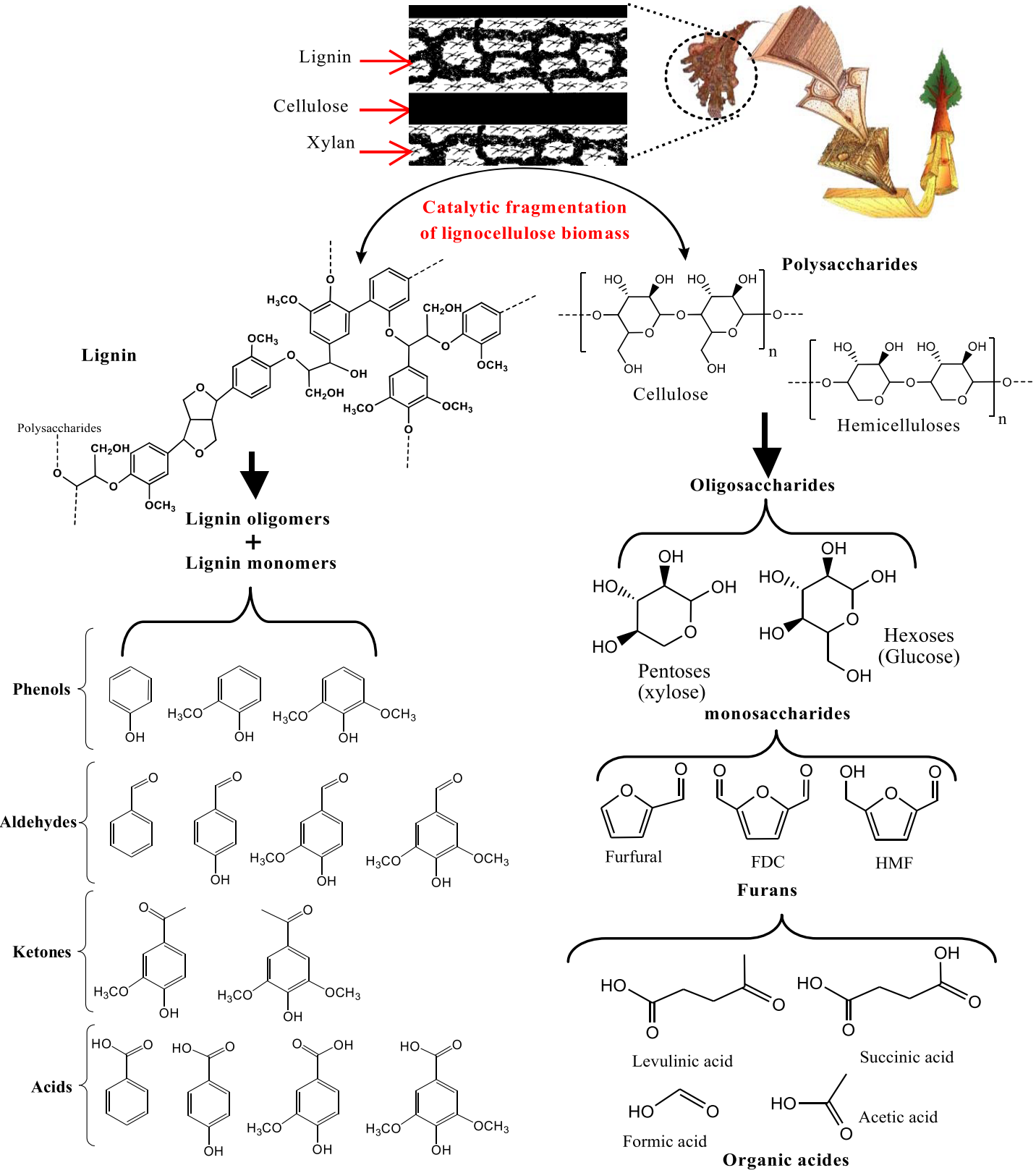

considerable interest for high-technology applications. ${ }^{19,20}$ On the other hand, in the catalysis area, few works have been published on the use of this kind of material in photocatalysis. Mondal et al. have developed a distinctive method for ZVO synthesis with a rare cubo-octahedral morphology. ${ }^{21}$ Then, ZVO was exploited as a photocatalyst for the photodegradation of several organic dye molecules under UV-light irradiation and with a high turnover number (TON). More recently, a facile, rapid, and solvent-free method to synthesize nanostructured ZVO has been reported. ${ }^{22}$ The authors of this study have highlighted the impact of the nature of the precursors used on the material morphology. The main ZVO synthesis methods reported in the literature are sol-gel ${ }^{23}$ hydrothermal method, ${ }^{19}$ co-precipitation, ${ }^{24}$ and solid-state synthesis. ${ }^{20}$ However, to the best of our knowledge, no study on the use of ZVO in heterogeneous catalysis for biomass upgrading has been reported yet. Herein, ZVO was synthesized, charac- terized, and used for the fractionation and conversion of poplar wood biomass via the depolymerization of lignin and carbohydrates.

\section{RESULTS AND DISCUSSION}

Material Characterization. Table 1 shows the chemical composition of the poplar wood sample we used in this study. Its average composition (dry weight basis) was $45 \%$ cellulose, $23 \%$ lignin, $23 \%$ hemicelluloses, and $10.2 \%$ others. This chemical composition is in good agreement with other values found in the literature. The degree of lignification was estimated by the Klason lignin and acetyl bromide methods. The cellulose content was estimated from the amount of glucose in the Klason lignin hydrolysates. The hemicellulose content was estimated from the amounts of xylose, arabinose, galactose, mannose, and uronic acids. Lignin is an aromatic polymer in which the guaiacyl (G)- and syringyl (S)-propane 
Table 1. Chemical Composition of the Untreated Poplar Wood Used in This Experiment (wt \%)

\begin{tabular}{|c|c|}
\hline \multicolumn{2}{|c|}{ lignin content } \\
\hline acetyl bromide & $22.6 \pm 3.8$ \\
\hline Klason lignin & $23.4 \pm 2.2$ \\
\hline$\beta-\mathrm{O}-4(\mu \mathrm{mol} / \mathrm{g}$ lignin $)$ & 2346 \\
\hline $\mathrm{S} / \mathrm{G}$ ratio & 1.36 \\
\hline \multicolumn{2}{|c|}{ carbohydrate content } \\
\hline cellulose & $44.8 \pm 2.5$ \\
\hline hemicelluloses & $23.4 \pm 3.1$ \\
\hline others & $10.2 \pm 4.1$ \\
\hline
\end{tabular}

monomer units are connected by both $\mathrm{C}-\mathrm{O}-\mathrm{C}$ and $\mathrm{C}-\mathrm{C}$ linkages, with carbonyl and methoxy functional groups. Poplar wood lignin is composed of $\mathrm{G}$ and $\mathrm{S}$ units with an $\mathrm{S} / \mathrm{G}$ ratio of 1.36. The $\beta-\mathrm{O}-4$ linkage (alkyl aryl ether, the most abundant structure in native lignin) content, determined by thioacidolysis, was $2350 \mu \mathrm{mol} / \mathrm{g}$ of lignin (Table 1 ), in agreement with previous works. ${ }^{5,25}$ Hence, the cleavage of $\mathrm{C}-\mathrm{O}-\mathrm{C}$ bonds and $\mathrm{C}-\mathrm{C}$ bonds $(\beta-\mathrm{O}-4, \beta-5, \beta-\beta, 5-\mathrm{O}-4$, and $5-5)$ of $\mathrm{G}-$ and $S$-propane units are important factors in chemical lignin depolymerization.

Figure 1 shows the X-ray diffraction (XRD) pattern of a representative sample $\left(\mathrm{Zn}_{3} \mathrm{~V}_{2} \mathrm{O}_{8}\right)$ obtained after its calcination

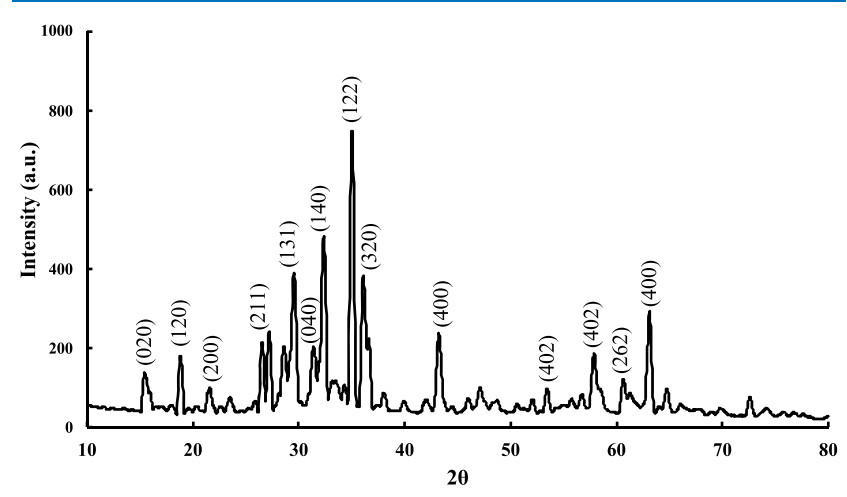

Figure 1. X-ray diffraction pattern of ZVO.

at $550{ }^{\circ} \mathrm{C}$. This analysis shows only one phase corresponding to the orthorhombic phase of $\mathrm{ZVO}\left(\mathrm{Zn}_{3} \mathrm{~V}_{2} \mathrm{O}_{8}\right)$, which is consistent with JCPDS card No. 34-0378. The lattice parameters are $a=8.306 \AA, b=11.540 \AA$, and $c=6.117 \AA$. The XRD pattern depicts that no impurities detectable by $\mathrm{XRD}$ are produced during the synthesis via the co-precipitation route. The peaks are relatively broad, which is characteristic of nanocrystalline particles. The average crystalline size was determined from the XRD spectrum by Scherrer's equation using EVA software. We obtained a size of $63 \mathrm{~nm}$.

The Brunauer-Emmett-Teller (BET) surface area of ZVO is $34 \mathrm{~m}^{2} / \mathrm{g}$ and its pore volume is $0.001609 \mathrm{~cm}^{3} / \mathrm{g}$. The nitrogen sorption isotherm of ZVO is of types III and IV (Figure S1), displaying the hysteresis loop $\mathrm{H} 3$ in the relative pressure range of $0.85-0.95$ and plateaus in the adsorption branches, indicating its intergranular porosity due to the formation of aggregates of plate-like particles forming slit-like pores. We note that the adsorbed volume remains low until $P$ / $P_{0}$ equals 0.85 , which corresponds to the constitution of a molecular monolayer. The adsorption of $\mathrm{N}_{2}$ is progressively increased to constitute a monolayer covering the entire external surface of the ZVO pores.
Figure 2a,b shows scanning electron microscopy (SEM) images of ZVO under both magnifications. These images of the as-obtained mixed oxide after calcination indicate a porous nanoplatelet-like morphology. The porous ZVO nanoplatelets have coarse surfaces. From these images, we can see that the porous nanoplatelets are composed of many ZVO nanocrystals. Transmission electron microscopy (TEM) analysis of ZVO revealed that the sample is well-nanostructured with an irregular morphology due to the particle's loose assemblage (Figure 2c,d). This observation can be explained by the Ostwald ripening phenomena. The particles of $\mathrm{ZVO}$ are very fine, and so they are agglomerated in the form of a superstructure (average size at ca. $100 \mathrm{~nm}$ ), but they are well-dispersed (Figure 2c).

Catalytic Fractionation and Conversion of Wood Biomass. The catalytic experiments were performed in a batch reactor, at 160,180 , and $200{ }^{\circ} \mathrm{C}$, in water $(\mathrm{pH}=7)$ with $10 \% \mathrm{O}_{2} / 90 \% \mathrm{~N}_{2}$ as the oxidant. The reactions were catalyzed by dispersed ZVO. After that, the reaction mixture was centrifuged to separate the insoluble fraction, which was then freeze-dried to yield the "residue" fraction. The low-molecularweight aromatic molecules (lignin) and furans (polysaccharides) were first extracted from the supernatant with dichloromethane $(\mathrm{DiCl})$ and then identified and quantified by gas chromatography (GC) coupled with mass detection. The aqueous phase (WSol) was also analyzed and quantified using high-performance liquid chromatography (HPLC) (Scheme 2 ). Figure 3 shows the distribution of the products of poplar biomass fractionation within the "residue": "WSol" and "DiCl" fractions. The catalytic reaction of delignification and fragmentation of lignocellulosic biomass performed with $\mathrm{ZVO} / \mathrm{O}_{2}$ as the catalyst system at $200{ }^{\circ} \mathrm{C}$ yielded $290 \mathrm{mg} / \mathrm{g}$ of residue, $368 \mathrm{mg} / \mathrm{g}$ of WSol, and $126 \mathrm{mg} / \mathrm{g}$ of $\mathrm{DiCl}$ compared, respectively, to 414,325 , and $74 \mathrm{mg} / \mathrm{g}$ without ZVO. The results of catalytic delignification and fractionation of biomass indicate clearly that the ZVO mixed oxide is an excellent heterogeneous catalyst for the oxidative fragmentation and depolymerization of lignin to aromatic monomers, with diluted oxygen, under a relatively low pressure.

GC-mass spectrometry (GCMS) analysis of the $\mathrm{DiCl}$ fractions was conducted to identify and quantify the yield of the major low-molecular-weight products (aromatics and furans) (Figure 4 and Table 2). In this study, the ecofriendly delignification of polar biomass and cleavage of lignin polymers by dispersed oxides "in situ" in the presence of oxygen gave several new products, such as alkylbenzenes, benzaldehyde, benzoic acid, vanillin, vanillic acid, phenol, guaiacol, syringone, acetophenone, and syringaldehyde (Table 2). The various compounds in the $\mathrm{DiCl}$ fraction were determined quantitatively by GC using standards under every reaction condition. Some products (e.g., catechol) may have been converted into gas, but the gas product was not analyzed. Kruse et al. have suggested that pyrocatechol could be converted into gases at high temperatures. $^{26}$

Figure 4 shows the yield of the $\mathrm{DiCl}$ fraction obtained after the reaction with $\mathrm{ZVO}$ in water at different temperatures for $240 \mathrm{~min}$. Over $\mathrm{ZVO}$ at $200{ }^{\circ} \mathrm{C}$, for $240 \mathrm{~min}$, poplar wood biomass delignification exceeded $97 \%$ (Table 3), with lignin conversion to identified aromatic compounds exceeding 56 $\mathrm{mg} / \mathrm{g}$ of biomass compared to only $32 \mathrm{mg} / \mathrm{g}$ of biomass without ZVO. This suggested that the lignin-wood matrix is more depolymerized "in situ, in biomass" over ZVO oxide compared to extracted lignin, which can be attributed to the 


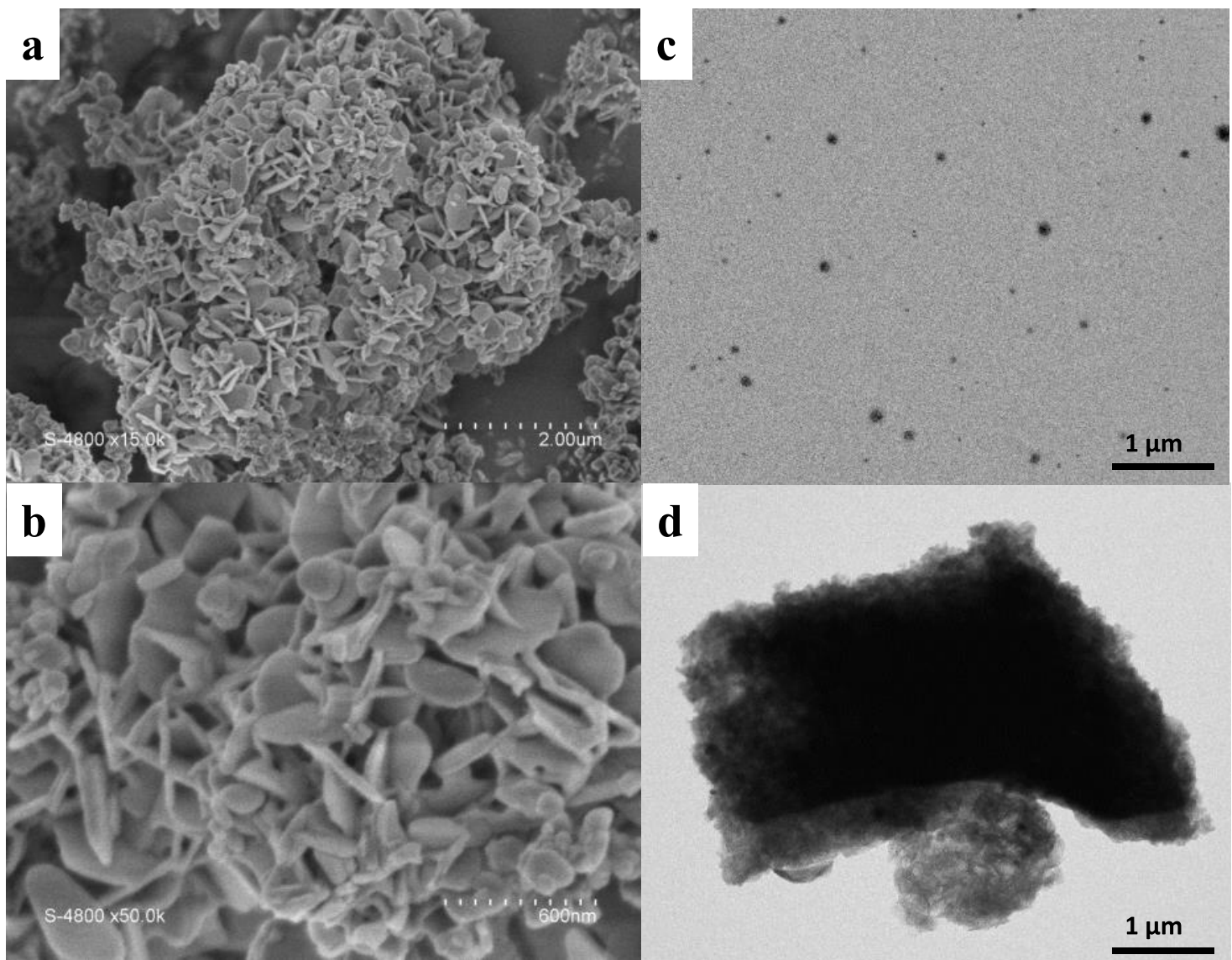

Figure 2. SEM (a, b), and TEM (c, d) images of nanostructured ZVO.

Scheme 2. Catalytic Fractionation Scheme of Poplar Wood Biomass

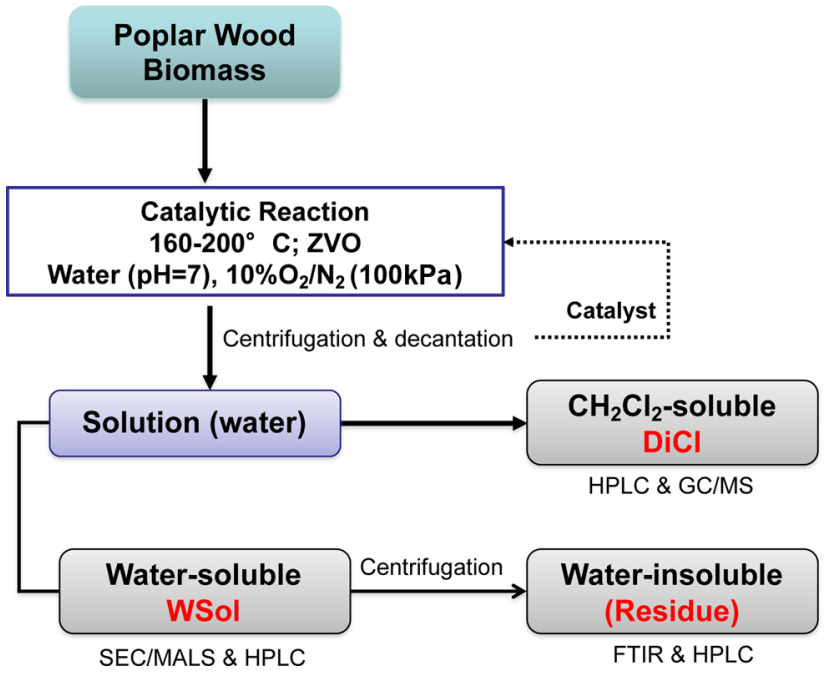

high $\beta-\mathrm{O}-4$ linkage content of the wood lignocellulosic matrix described in previous works. ${ }^{27-29}$ The depolymerization of wood-lignin polymers over ZVO mixed oxide in water under oxygen at 160,180 , and $200{ }^{\circ} \mathrm{C}$ showed, respectively, 8 , 15 , and $24 \% \mathrm{w} / \mathrm{w}$ conversion of the initial lignin in wood.

The catalytic oxidation of $\mathrm{C}-\mathrm{O}-\mathrm{C}$ bonds in the lignin polymer released vanillin, phenol, benzoic acid, and syringaldehyde as the major products, although intermediate products of oxidation and decomposition of these compounds

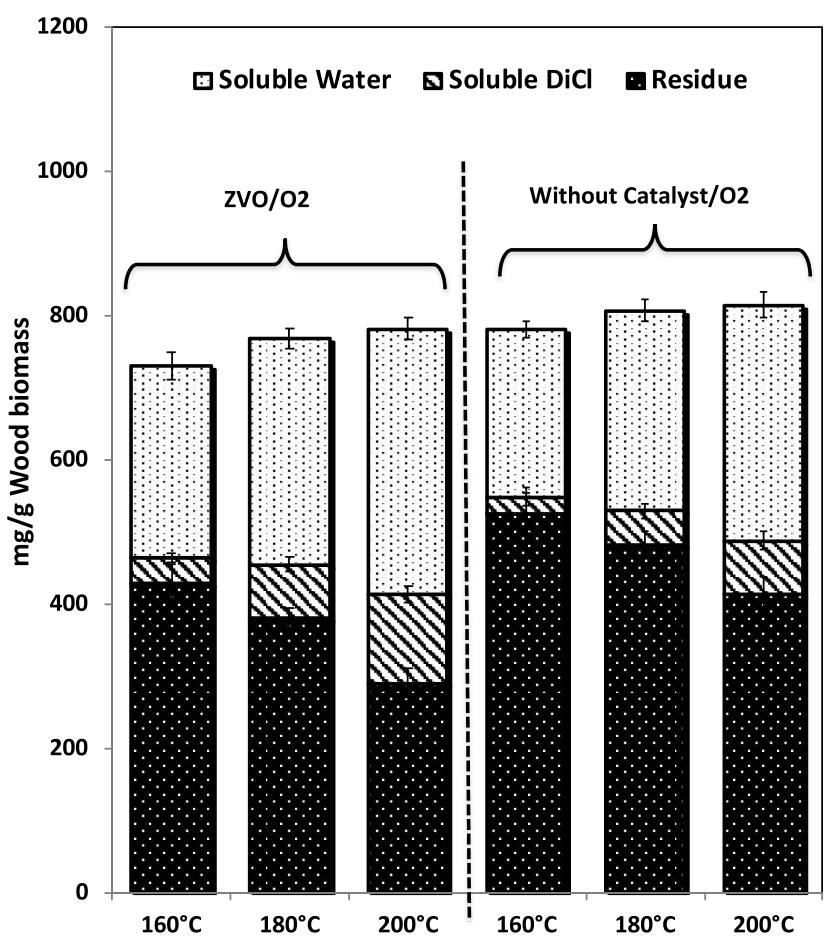

Figure 3. Recovery $(\mathrm{mg} / \mathrm{g}$ of wood) of the residue, water-soluble fraction (WSol), and dichloromethane-soluble fraction (DiCl) in catalytic experiments performed with $\mathrm{ZVO}$ oxide and without the catalyst in water $(\mathrm{pH}=7)$, with $10 \% \mathrm{O}_{2} / 90 \% \mathrm{~N}_{2}(100 \mathrm{kPa})$ as the oxidant at 160,180 , and $200{ }^{\circ} \mathrm{C}$. 


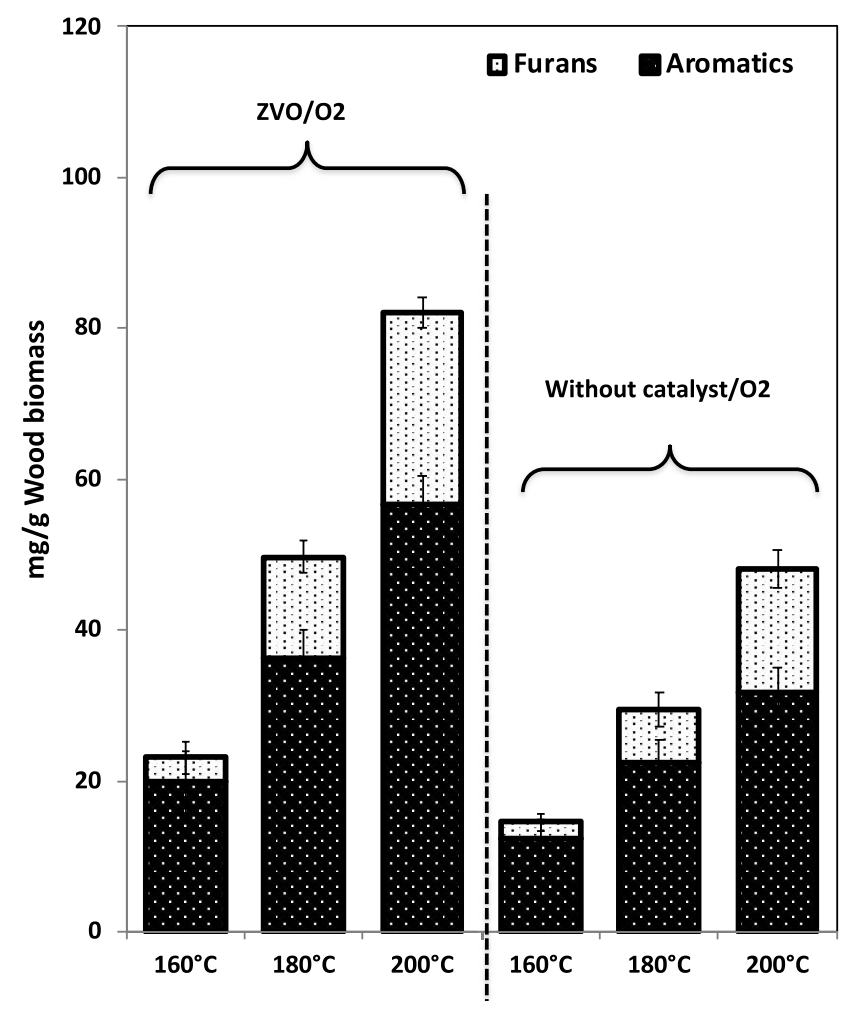

Figure 4. Recovery (mg/g of wood) of aromatics (lignin) and furans (polysaccharides) in the dichloromethane-soluble fraction $(\mathrm{DiCl})$ in catalytic experiments performed with or without $\mathrm{ZVO}$ oxide as the catalyst in water $(\mathrm{pH}=7)$, with $10 \% \mathrm{O}_{2} / 90 \% \mathrm{~N}_{2}(100 \mathrm{kPa})$ as the oxidant at 160,180 , and $200{ }^{\circ} \mathrm{C}$.

were obtained in different amounts depending on the reaction conditions. The depolymerization of biomass by $\mathrm{ZVO}$ in water (100\%, with $10 \% \mathrm{O}_{2} / 90 \% \mathrm{~N}_{2}$ as the oxidant at $200{ }^{\circ} \mathrm{C}$ ) showed 18.07, 20.61, 13.53, 7.86, 5.92, and 4.31\% selectivities to vanillin, syringaldehyde, 5-hydroxymethylfurfural (HMF), phenol, acetosyringone, and benzoic acid, respectively. Aromatics represent about $24 \% \mathrm{w} / \mathrm{w}$ of the initial lignin (Table 2 and Figure 4). These results indicate that the combination of $\mathrm{ZVO}$ with the $\mathrm{O}_{2}$ oxidant greatly improved the biomass delignification and lignin depolymerization "in situ" for functional monomer production in comparison with previous works (Table S2).

The catalytic reaction of delignification and fragmentation of lignocellulosic biomass performed with $\mathrm{ZVO} / \mathrm{O}_{2}$ as the catalyst system was carried out at three different temperatures: 160,

Table 3. Results of Poplar Wood Delignification Catalyzed by Dispersed Bimetallic ZVO Oxide in Water $(\mathrm{pH}=7$, Wood/Catalyst Ratio 5:1), with $10 \% \mathrm{O}_{2} / 90 \% \mathrm{~N}_{2}$ at 160 , 180 , and $200{ }^{\circ} \mathrm{C}$

\begin{tabular}{cccc}
$T\left({ }^{\circ} \mathrm{C}\right)$ & cellulose yield (\%) & lignin content $(\%)$ & $\begin{array}{c}\text { delignification degree } \\
(\%)\end{array}$ \\
160 & 79.2 & 16.0 & 61.9 \\
180 & 74.5 & 9.4 & 82.3 \\
200 & 65.6 & 2.0 & 97.2 \\
\hline
\end{tabular}

180 , and $200{ }^{\circ} \mathrm{C}$. After dichloromethane extraction, the watersoluble fractions yielded (WSol) were analyzed.

Figure 5 shows the chemical composition of the watersoluble fraction (WSol), which contained a mixture of sugar

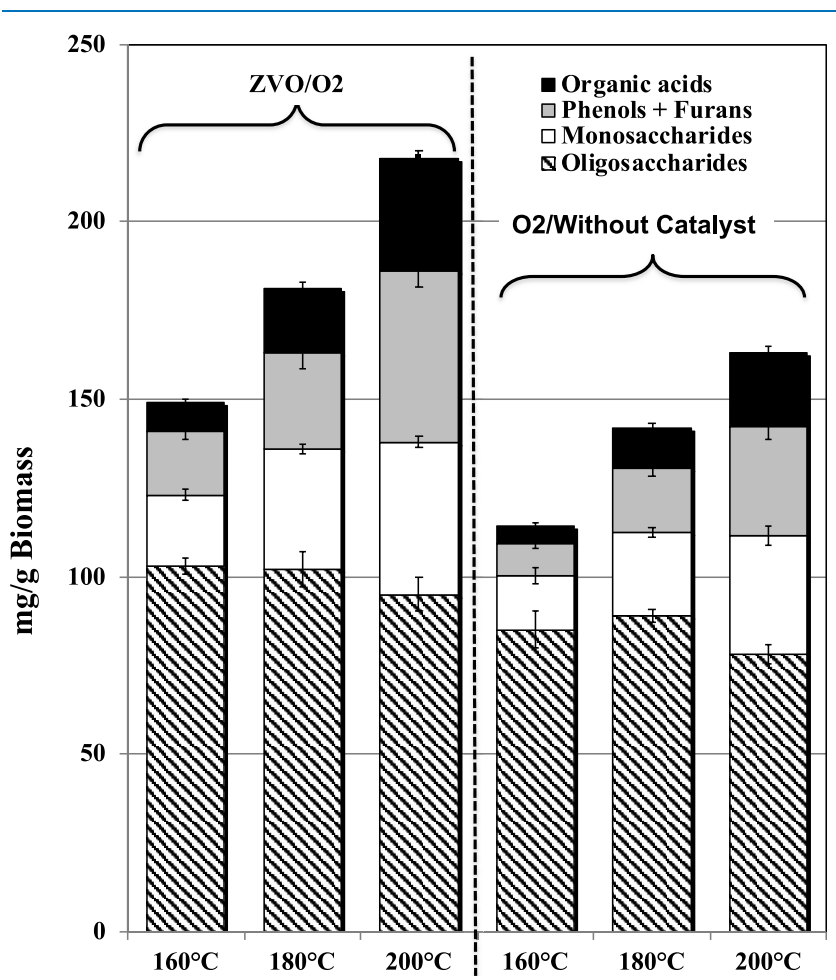

Figure 5. Recovery (mg/g of wood) of organic acids, monosaccharides, and oligosaccharides in the water-soluble fraction (WSol) in catalytic experiments performed with ZVO oxide and without the catalyst in water $(\mathrm{pH}=7)$, with $10 \% \mathrm{O}_{2} / 90 \% \mathrm{~N}_{2}(100 \mathrm{kPa})$ as the oxidant at 160,180 , and $200{ }^{\circ} \mathrm{C}$.

Table 2. Selectivity of Major Products Resulting from the Poplar Wood Biomass Catalytic Oxidation over ZVO in Water $(100 \%, \mathrm{pH}=7)$ under $100 \mathrm{kPa}$ of $10 \% \mathrm{O}_{2} / 90 \% \mathrm{~N}_{2}$

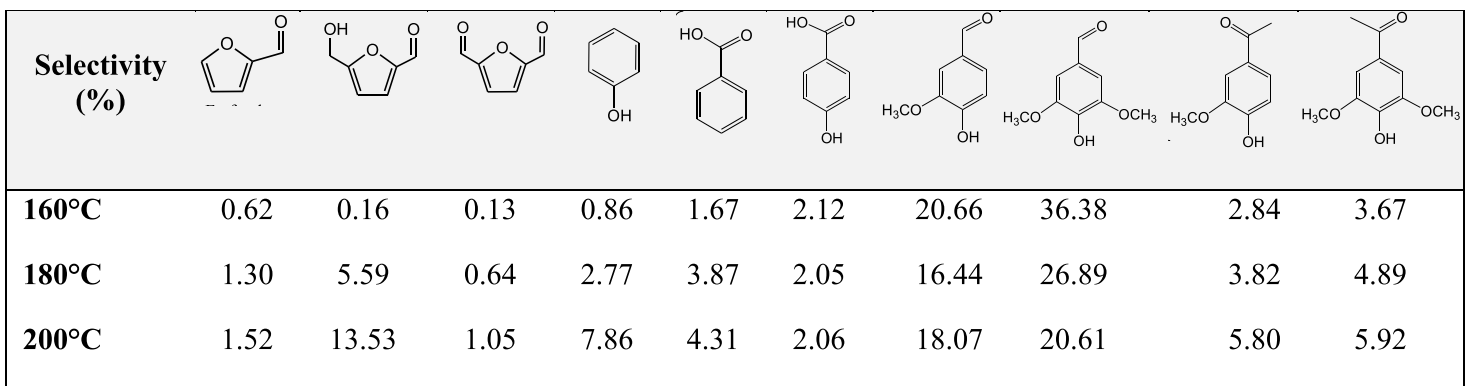




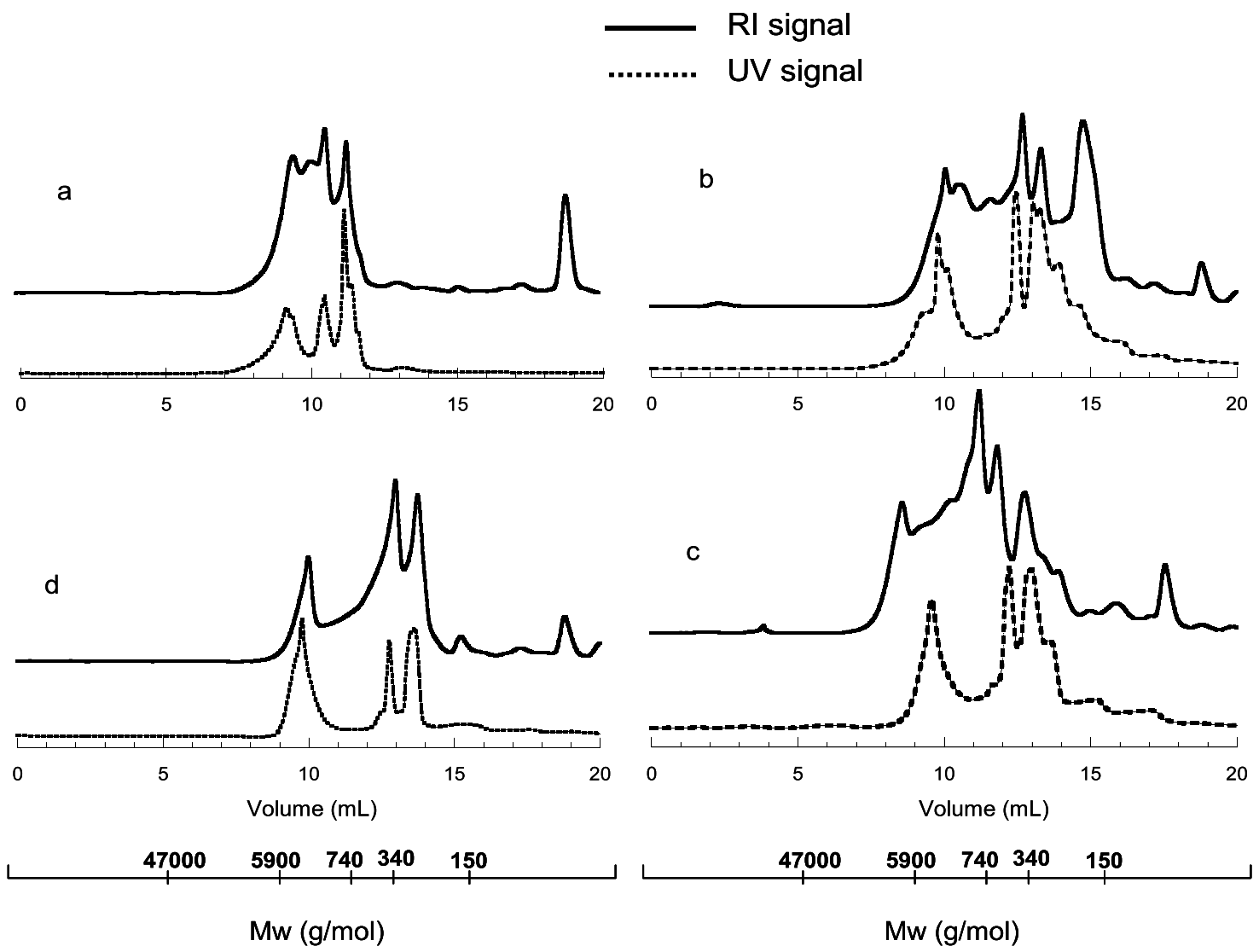

Figure 6. Molecular-weight distribution of the water-soluble fraction (WSol) obtained by the noncatalytic delignification/fragmentation of wood (a) performed in water $(100 \%, \mathrm{pH}=7)$, with $10 \% \mathrm{O}_{2} / 90 \% \mathrm{~N}_{2}(100 \mathrm{kPa})$ at $200{ }^{\circ} \mathrm{C}$, and $(\mathrm{b}, \mathrm{c}, \mathrm{d})$ with $\mathrm{ZVO}$ in water $(100 \%, \mathrm{pH}=7)$, with $10 \%$ $\mathrm{O}_{2} / 90 \% \mathrm{~N}_{2}$ at 160,180 , and $200{ }^{\circ} \mathrm{C}$ respectively.

oligomers, monosaccharides (xylose and glucose), organic acids (acetic acid, formic acid, etc.), furfural, HMF, and some phenols. All of them were detected by HPLC, as described before. It was found that the composition of these compounds depended on the catalytic reaction conditions. Most of the hemicelluloses/cellulose found in the liquid fraction were found as oligomers, representing $65-70 \%$ of the liquid fraction depending on the severity of the treatment (Figure 5). Cellulose mostly remained in the residue $(66-80 \%$ of the initial cellulose), and only a small part was depolymerized into oligomers, glucose, or HMF. The maximal percentage of soluble gluco-oligosaccharides recovered from cellulose varied from 4 to $15 \%$ of the initial cellulose when the temperature varied from 160 to $200{ }^{\circ} \mathrm{C}$. Less gluco-oligosaccharides and glucose were released from the most lignified materials. In contrast, hemicelluloses are readily depolymerized and dissolved at the different temperatures that we used in this study. Xylan is the main component in the hemicelluloses of the poplar wood we used. The maximal yield of xylan solubilization in the form of xylo-oligosaccharides was obtained after $4 \mathrm{~h}$ at $160{ }^{\circ} \mathrm{C}$, in comparison with the experiments performed at 180 and $200{ }^{\circ} \mathrm{C}$. Increasing the temperature resulted in lower xylo-oligosaccharide yields, especially at 200 ${ }^{\circ} \mathrm{C}$. Garrote et al. ${ }^{30}$ and Conner et al. ${ }^{31}$ reported that the percentages of xylo-oligosaccharide recovery from eucalypt wood and hardwood were estimated respectively to be 65 and $69 \%$. Liu and Wyman ${ }^{32}$ also reported that the disappearance of xylan increased at both temperatures and confirmed that xylan is mostly solubilized as oligomers. The yield of xylooligosaccharides obtained in this study varied from 48 to
$27 \%$ of the initial xylan when the temperature changed from 160 to $200{ }^{\circ} \mathrm{C}$, in good agreement with the different cited studies. In addition, the residual xylan varied from 36 to $4 \%$ of the initial xylan when the temperature changed from 160 to $200{ }^{\circ} \mathrm{C}$. The yields of xylose and glucose released in the liquid fraction (WSol) were not high because these compounds readily converted to furfural and organic acids under a high temperature and pressure. Dehydration of carbohydrates and carbohydrate-derived molecules encompasses an important class of reactions in the field of sugar chemistry. As shown in Scheme 1, sugars can be dehydrated to form furan compounds such as furfural and HMF, which can be further converted into organic acids or other products. The liquid fraction contains some furans and phenolic compounds formed respectively from carbohydrates and lignin, which are not well-separated on HPLC. During the catalytic reaction, lignin was depolymerized and a small fraction of low-molar-mass phenolics dissolved. A part of the lignin is known to be covalently bound to xylan. Therefore, some xylo-oligosaccharides might contain such phenolics. Figure 5 also shows the distribution of phenols, furans, and organic acids in the liquid fraction from catalytic experiments of delignification and fragmentation of poplar wood as a function of temperature. The total recovery of the phenols and furans from catalytic reactions increased with increasing temperature to reach $10-25 \%$ of the liquid fraction when the temperature increased from 160 to $200{ }^{\circ} \mathrm{C}$. The thermal catalytic reaction of pentoses and hexoses leads to the formation of three interesting molecule platforms: furfural (2furancarboxaldehyde) arising from the dehydration of pentoses (i.e., xylose), 5-hydroxymethylfurfural (HMF) arising from the 
dehydration of hexoses (i.e., glucose), and levulinic acid formed from the hydration of HMF. The bimetallic dispersedoxide-catalyzed dehydration leads, besides HMF and furfural, to traces of various other products, such as 2,5-furandicarboxaldehyde (FDC), levulinic acid, succinic acid, and formic and acetic acids arising from the hydration and oxidation of HMF and furfural. ${ }^{33-35}$ The yield of organic acids increases from 2 to $15 \%$ of the liquid fraction when the temperature changes from 160 to $200{ }^{\circ} \mathrm{C}$. Figures 4 and 5 show the yield of furan derivatives extracted with dichloromethane at different temperatures. A significant amount of $\mathrm{HMF}$ was produced during the catalytic oxidation with $\mathrm{ZVO} / \mathrm{O}_{2}$ as the catalyst system at $200{ }^{\circ} \mathrm{C}$, with yields of $25 \mathrm{mg} / \mathrm{g}$ of initial wood compared to only $14 \mathrm{mg} / \mathrm{g}$ without ZVO (Figure 4 and Table 2 ). The yield decreased to $4 \mathrm{mg} / \mathrm{g}$ at $160{ }^{\circ} \mathrm{C}$ due to the crystalline structure of cellulose, which normally starts to dissolve in water at high temperatures $\left(\geq 180{ }^{\circ} \mathrm{C}\right)$ under neutral conditions. The results show the formation of FDC, amounting to about $0.5 \mathrm{mg} / \mathrm{g}$ of initial wood by oxidizing $\mathrm{HMF}$ in water with $\mathrm{ZVO} / \mathrm{O}_{2}$ as the catalyst system. In contrast, a small production of furfural was observed at the lowest temperatures, with a maximum of $1.8 \mathrm{mg} / \mathrm{g}$ of initial wood at $180{ }^{\circ} \mathrm{C}$. It is likely that furfural and HMF are catalytically converted at high temperatures into organic acids and light products through a sequential oxidation pathway, in good agreement with the organic acid concentration observed in the liquid fraction. HMF is one of the new interesting molecules derived from lignocellulosic biomass. The most versatile intermediate chemicals of high industrial potential that can be generated from HMF in simple large-scale transformation are 2,5-furandicarboxylic acids and FDC.

The dehydration of hexoses (sugars- $\mathrm{C}_{6}$ ) into HMF has been studied in water, organic solvents, biphasic systems, ionic liquids, and near-critical or supercritical water, using a variety of catalysts. $^{36,37}$ The results shown on Figures 4 and 5 clearly indicate that dispersed bimetallic oxides "ZVO" with oxygen as the oxidant could be a promising technology for converting carbohydrates in water into HMF and diesel fuel additives. Figure 6 shows the molecular-weight distribution of the watersoluble fraction (WSol) obtained by the noncatalytic delignification/fragmentation of wood performed in water (100\%, pH = 7), with $10 \% \mathrm{O}_{2} / 90 \% \mathrm{~N}_{2}(100 \mathrm{kPa})$ at $200{ }^{\circ} \mathrm{C}$, and performed by dispersed $\mathrm{ZVO}$ oxide in water $(100 \%, \mathrm{pH}=$ 7), with $10 \% \mathrm{O}_{2} / 90 \% \mathrm{~N}_{2}(100 \mathrm{kPa})$ at 160,180 , and $200{ }^{\circ} \mathrm{C}$. UV detection was used to quantify phenols and furans in the samples, while a refractive index (RI) detector was used to quantify carbohydrates. The molar mass distribution in WSol obtained by gel permeation chromatography (GPC) (Figure 6) was similar for all oligosaccharides, showing several molecular peaks $\left(M_{\mathrm{w}}\right)$ in various proportions, which depended on the reaction conditions. It can be seen in Figure 6 that a fraction of the products was of very small molecular mass (40$300 \mathrm{~g} / \mathrm{mol}$ ), including degradation products, and that monoand disaccharides were mostly present at $160{ }^{\circ} \mathrm{C}$. The presence of oligosaccharides $(300-6000 \mathrm{~g} / \mathrm{mol})$, especially at $200{ }^{\circ} \mathrm{C}$, was in agreement with the recovery yield of oligosaccharides from treated wood at $200{ }^{\circ} \mathrm{C}$ in the presence of $\mathrm{ZVO} / \mathrm{O}_{2}$ (Figure 5). The UV elution profiles represent the UVabsorbing materials (such as some furans, phenols, etc.). This confirms that some oligosaccharides might contain such phenolic and/or absorbing functional groups (oxidation of $\mathrm{OH}$ groups of monosaccharides), especially after the treatment at $200{ }^{\circ} \mathrm{C}$, in agreement with the concentration of furans and phenols determined in the liquid fraction. The fragmentation of lignocellulosic biomass in water $(\mathrm{pH}=7)$ with bimetallic dispersed oxide takes place in slightly acidic media due to the partial cleavage of glycosidic bonds, followed by successive reactions of oxidation and dehydration that release furans, organic acids, and functional oligosaccharides. By controlling the temperature and reaction time, it is possible to influence the characteristics of the oligosaccharides such as their molar mass distribution. The catalytic fragmentation of biomass in water could also be a promising technology for converting agro-food byproducts into useful food ingredients, for example, functional oligosaccharides. The yield of the residue fraction from catalytic experiments of delignification and fragmentation of poplar wood as a function of temperature is shown in Table 3. The total recovery of the residue from catalytic reactions decreased with increasing temperature to reach $35-55 \%$ of the initial wood. The resulting residue contained a mixture of cellulose, hemicelluloses, and lignin. The recovery of these biopolymers is highly dependent on the severity of the experiments, for example, temperature, which is in agreement with previous reports. ${ }^{6,13,38}$ In all experiments, most of the cellulose remained in the residue at different temperatures. The total cellulose yield in the solid phase recovered from wood after catalytic reaction varied from 79.2 to $65.6 \%$ of the initial cellulose when the temperature changed from 160 to $200{ }^{\circ} \mathrm{C}$. In contrast, the lignin and xylan contents of the residue fraction decreased respectively from 16 and $17 \%$ under low-severity conditions to 2 and $3 \%$ under high-severity conditions.

The experiments showed that more than $60 \%$ of the initial lignin and hemicelluloses could be found in the liquid fraction (as free phenols, xylose, furfural, HMF, organic acids, or oligosaccharides). However, when the wood was treated with $\mathrm{ZVO} / \mathrm{O}_{2}$ as a catalyst system at $200{ }^{\circ} \mathrm{C}$ for $4 \mathrm{~h}$, the lignin and xylan were more depolymerized than at 160 and $180^{\circ} \mathrm{C}$ and in experiments realized without a catalyst. Analyses also showed that the chemical composition of the residue fraction from wood treated at $200{ }^{\circ} \mathrm{C}$ with $\mathrm{ZVO} / \mathrm{O}_{2}$ as the catalyst system was $65.6 \%$ cellulose, $2.6 \%$ xylan, and $2.0 \%$ lignin. These results explain the better delignification of wood obtained at $200{ }^{\circ} \mathrm{C}$ for $4 \mathrm{~h}$ when performed with ZVO $(\geq 97)$ (see Table 3 ). The degrees of delignification of wood obtained with $\mathrm{ZVO} / \mathrm{O}_{2}$ as the catalyst system at different temperatures in water were better in comparison with those reported in the literature. When aspen wood chips were steam-exploded at $205{ }^{\circ} \mathrm{C}$ for 5 min, a delignification degree of $67 \%$ was obtained after dioxane-water (9:1) extraction. ${ }^{39}$ However, when molybdovanadophosphate was used as the catalyst for wood delignification for $5 \mathrm{~h}$ at $100{ }^{\circ} \mathrm{C}, \mathrm{pH}=1.8$, under $70 \mathrm{kPa}$ $\mathrm{PO}_{2}$, the degrees of delignification were 64 and $78 \%$ in water and water $/ \mathrm{EtOH}(50 / 50, \mathrm{v} / \mathrm{v})$, respectively. It is remarkable to observe that under mild conditions [water; $\mathrm{pH}=7 ; p\left(\mathrm{O}_{2}\right)=$ $10 \mathrm{kPa} ; 4 \mathrm{~h}$ ] with $\mathrm{ZVO} / \mathrm{O}_{2}$ as the catalyst, lignin was totally depolymerized into low- and high-molecular-weight products, which can be developed in other technological applications.

Fourier transform infrared (FTIR) spectra of untreated poplar wood (a), residues from reactions at $160{ }^{\circ} \mathrm{C}(\mathrm{b}), 180$ ${ }^{\circ} \mathrm{C}(\mathrm{c})$, and $200{ }^{\circ} \mathrm{C}(\mathrm{d})$, and cellulose (e) are shown in Figure 7. The maxima between 2000 and $800 \mathrm{~cm}^{-1}$ have been assigned. ${ }^{40-42}$ The spectra of wood treated with $\mathrm{Zn}_{3} \mathrm{~V}_{2} \mathrm{O}_{8}$ as a catalyst system at 160,180 , and $200{ }^{\circ} \mathrm{C}$ are shown in Figure $7 \mathrm{~b}-\mathrm{d}$. Different bands obtained and their functional groups are presented in Table 4. 


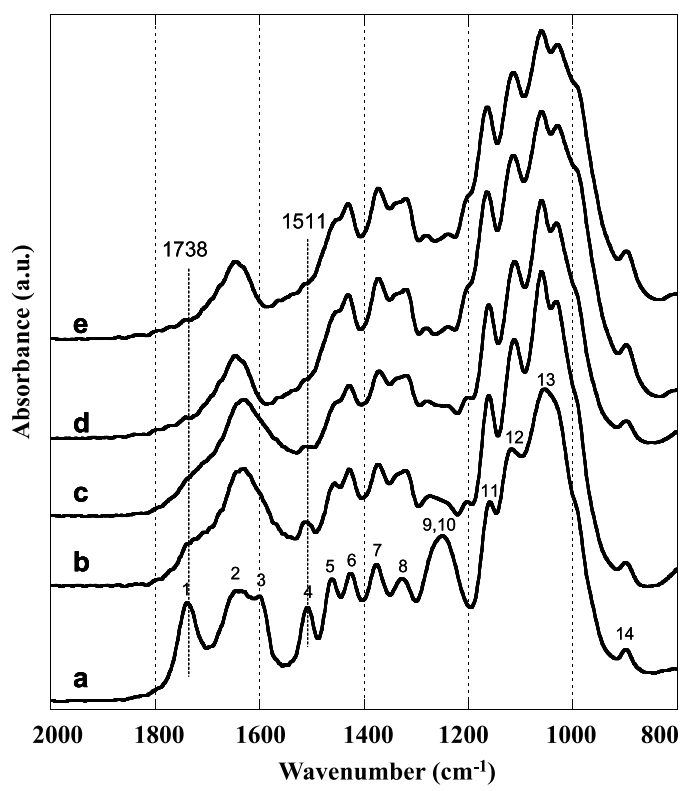

Figure 7. FTIR spectra of (a) untreated poplar wood, (b) residue-160 ${ }^{\circ} \mathrm{C}$, (c) residue- $180{ }^{\circ} \mathrm{C}$, and (d) residue-200 ${ }^{\circ} \mathrm{C}$ after catalytic treatment over ZVO oxide in water $(100 \%, \mathrm{pH}=7)$, with $10 \% \mathrm{O}_{2} /$ $90 \% \mathrm{~N}_{2}(100 \mathrm{kPa})$, and (e) microcrystalline commercial cellulose in the fingerprint region between 2000 and $800 \mathrm{~cm}^{-1}$.

Table 4. FTIR Adsorption Bands and Their Functional Groups

\begin{tabular}{lll}
$\begin{array}{l}\text { adsorption } \\
\text { band }\left(\mathrm{cm}^{-1}\right)\end{array}$ & \multicolumn{1}{c}{ functional group } & reference \\
$1738 / 1734$ & unconjugated C=O in xylans (hemicelluloses) & 1 \\
1650 & adsorbed O-H and conjugated C-O & 2 \\
1596 and & aromatic skeletal vibration in lignin & 3 and 4 \\
$1505 / 1511$ & & 5 and 6 \\
1462 and & C-H deformation in lignin and carbohydrates \\
1425 & C-H deformation in cellulose and hemicelluloses & 7 \\
1375 & C-H vibration in cellulose and C-O vibration in & 8 \\
$1330 / 1320$ & syringyl derivatives & \\
1268 & guaiacyl ring breathing; C-O stretch in lignin and & 9 \\
& in guaiacyl aromatic methoxyl groups & \\
1244 & Syringyl ring and C-O stretch in lignin and xylan & 10 \\
1158 & C-O-C vibration in cellulose and hemicelluloses & 11 \\
1122 & aromatic skeletal and C-O stretch & 12 \\
1048 & C-O stretch in cellulose and hemicelluloses & 13 \\
898 & C-H deformation in cellulose & 14 \\
1738 & the higher xylan content in untreated poplar wood & 1 \\
1511 and & the higher lignin content & 4 \\
1268 & &
\end{tabular}

Significant changes in the FTIR spectra can be seen according to the reaction conditions. Figure 7 shows that the intensities of xylan bands at $1738 \mathrm{~cm}^{-1}$ and lignin bands at $1511,{ }^{4} 1268,9$ and $1244 \mathrm{~cm}^{-110}$ decrease significantly when the temperature increases from 160 to $200{ }^{\circ} \mathrm{C}$. Infrared spectroscopy has previously been used to determine the lignin content in pulp, paper, and wood. ${ }^{41,42}$ The $1505-1515 \mathrm{~cm}^{-1}$ peak is often taken as a reference for lignin and the 1738, 1158, or 898 $\mathrm{cm}^{-1}$ peaks as the polysaccharide reference. Rodrigues et al. used FTIR spectroscopy to quantitatively determine lignin in Eucalyptus globulus using carbohydrate peaks at 1160 and 898 $\mathrm{cm}^{-1}$ as references against lignin peaks at 1505 and 1330 $\mathrm{cm}^{-1} .{ }^{42}$ The average relative intensities of lignin peaks at 1511 $\mathrm{cm}^{-1}$ against carbohydrate peaks at 1375,1160 , and $897 \mathrm{~cm}^{-1}$ were calculated using peak areas for residue fractions recovered from wood treated at 160,180 , and $200{ }^{\circ} \mathrm{C}$ in the presence of $\mathrm{ZVO} / \mathrm{O}_{2}$ for $240 \mathrm{~min}$ (Figure S2). The increase of the ligninto-carbohydrate ratio with temperature confirmed xylan and lignin depolymerization during the reaction catalyzed by ZVO. The depolymerization of lignin and xylan polymers to monomers and oligomers during the catalytic reaction performed with $\mathrm{ZVO} / \mathrm{O}_{2}$ as the catalyst system is in agreement with preceding results. In the case of the residue recovered from wood treated with $\mathrm{ZVO} / \mathrm{O}_{2}$ at $200{ }^{\circ} \mathrm{C}$, many similarities can be seen between the spectrum of the residue and that of microcrystalline cellulose (Figure 7), indicating a selective removal of xylan and lignin. This suggests that the solid fraction consists essentially of cellulose ( $96 \%)$ with some lignin and xylan impurities, in agreement with sugar analysis. Furthermore, reactions catalyzed at $200{ }^{\circ} \mathrm{C}$ by ZVO in the presence of $\mathrm{O}_{2}$ produced high-molar-mass oligosaccharides and high concentrations of HMF, vanillin, syringaldehyde, etc. without modifying the cellulose ( $\sim 66 \%$ of the initial cellulose). Lignin was chemically depolymerized during the catalytic delignification process, by the cleavage of $\beta-\mathrm{O}-4$ linkages and/or demethoxylation. We calculated the ratios of the height of lignin peaks at $1511 \mathrm{~cm}^{-1}$ against peaks at 1462 and 1425 $\mathrm{cm}^{-1}$ (due to $\mathrm{C}-\mathrm{H}$ and the deformation of methyl and methylene). The ratios of the peak heights at 1511 and 1462 decreased from 0.74 to 0.72 and 0.62 at 160 and $180{ }^{\circ} \mathrm{C}$, respectively, whereas at $200{ }^{\circ} \mathrm{C}$, this ratio was lowered down to 0.22 after catalytic delignification of wood in the presence of the $\mathrm{ZVO} / \mathrm{O}_{2}$ catalyst system (data not shown). In contrast, the ratio between peaks at 1511 and $1427 \mathrm{~cm}^{-1}$ decreased linearly from 1.55 with untreated wood to $0.59,0.28$, and 0.03 after treatment in the presence of $\mathrm{ZVO} / \mathrm{O}_{2}$ at 160,180 , and $200{ }^{\circ} \mathrm{C}$, respectively (data not shown). There was only a small decrease in the 1511 vs 1462 peak height ratio after reactions at 160 and $180{ }^{\circ} \mathrm{C}$ in comparison with the catalytic reaction performed at $200{ }^{\circ} \mathrm{C}$, which may be due to lignin demethylation rather than due to the cleavage of lignin $\beta-\mathrm{O}-4$ linkages and xylan depolymerization. It is evident that the alkylation reaction with methanol results certainly from demethoxylation by the cleavage of $\mathrm{C}-\mathrm{O}-\mathrm{C}$ aromatic bonds of the methoxy group $-\mathrm{C}-\mathrm{O}-\mathrm{CH}_{3}{ }^{43}$ The high decrease in the $I_{1427} / I_{1511}$ ratio may be attributed to the cleavage of lignin $\beta-\mathrm{O}-4$ linkages and xylan glycosidic bands, as observed in preceding results (Figures 3-5).

Mass Balance. Figure 8 shows the mass balance of wood fractionation in the presence of $\mathrm{ZVO} / \mathrm{O}_{2}$ at $200{ }^{\circ} \mathrm{C}$, which resulted in high lignin yields. This confirmed the efficiency of this system for lignin-biomass depolymerization. Based on the method used by Cheng et al., ${ }^{44}$ the proposed process showed a yield of $79.7 \%$ of the initial mass of poplar biomass, which is a good mass balance for the lignocellulosic biorefinery process. ${ }^{45}$ The residue obtained in this experiment (Figure 3) was composed of $29.56 \%$ cellulose, $2 \%$ lignin, and $2.6 \%$ xylan. The corresponding delignification reached $97 \%$, and the hemicellulose removal was estimated to be $88 \%$. A mass loss of $21 \%$ detected was corresponding to 15,4 , and $0.7 \%$ of cellulose, hemicelluloses, and lignin, respectively. These results confirmed that this lack corresponds only to holocellulose-rich residues, which is due probably to the separation and recuperation of the residue "cellulose" and the catalyst using different washing and filtration steps for different conditions (Figure 3). 


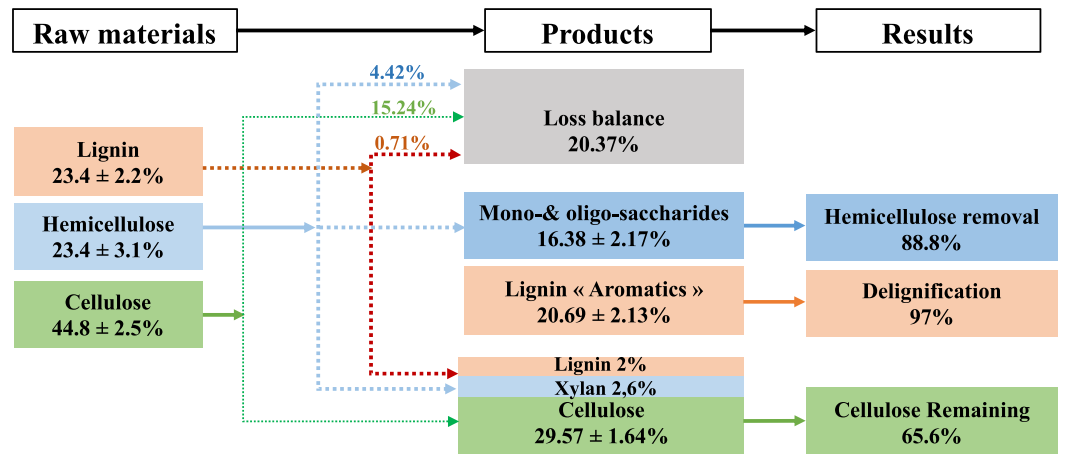

Figure 8. Mass balance for the fractionation process with the ZVO catalyst at $200{ }^{\circ} \mathrm{C}$.

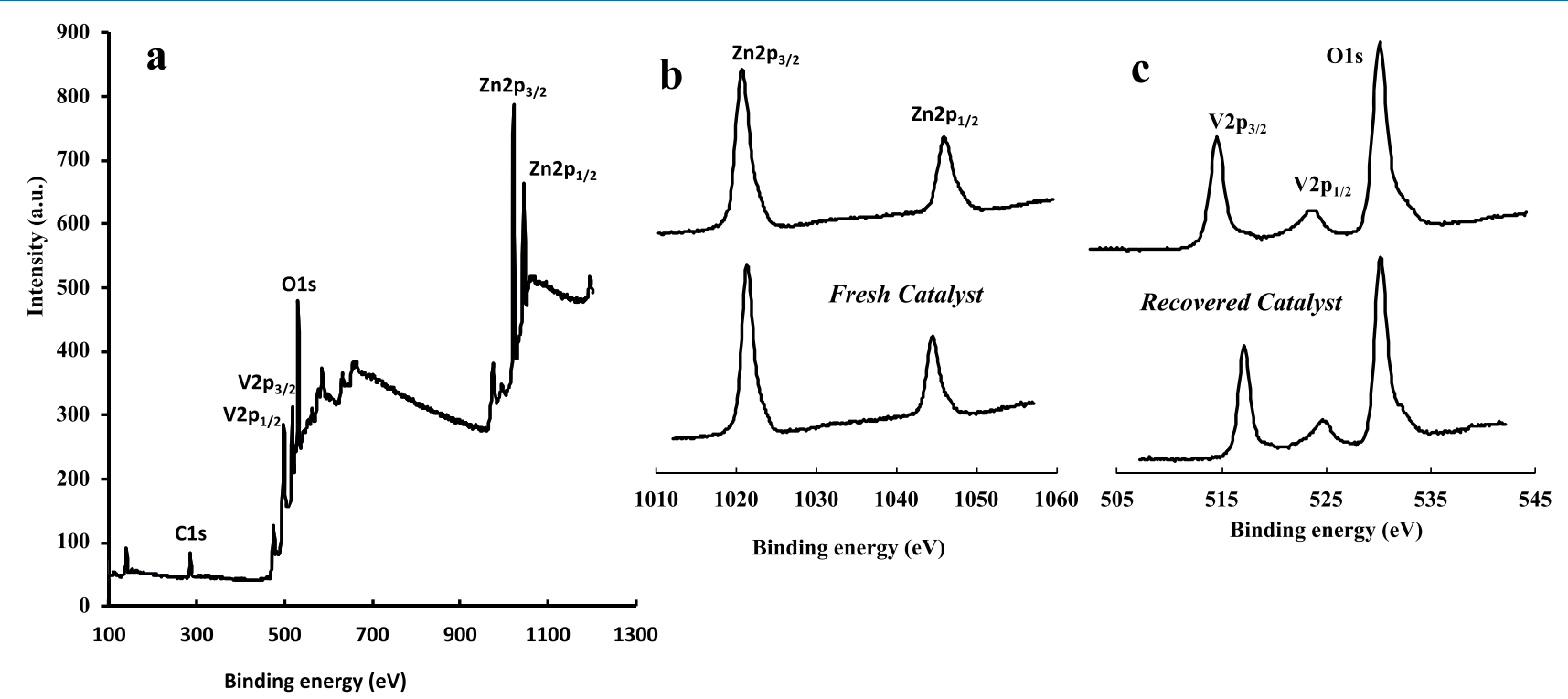

Figure 9. XPS spectra of the (a) survey spectrum, (b) Zn 2p, and (c) V 2p and O 1s.

Table 5. Delignification Degree, Lignin Conversion, and Selectively of the Major Products Resulting from the Poplar Wood Biomass Catalytic Oxidation over Recovered ZVO in Water $(100 \%, \mathrm{pH}=7)$ under $100 \mathrm{kPa}$ of $10 \% \mathrm{O}_{2} / 90 \% \mathrm{~N}_{2}$

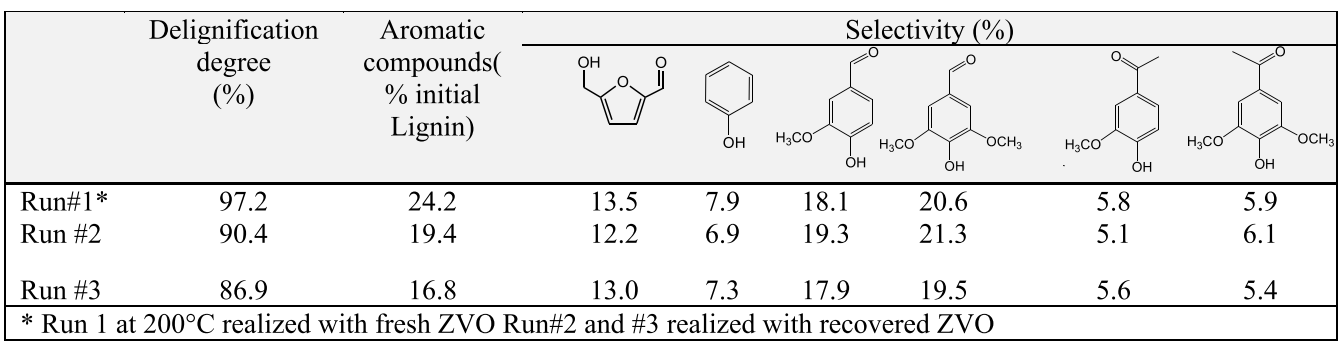

Catalytic Performance and Reuse of the ZVO System. The obtained results confirmed that the cleavage and depolymerization of lignin in situ (one pot: extraction + depolymerization) is a better strategy for lignin conversion to value-added chemicals compared to the depolymerization of extracted lignin. Indeed, lignin conversion depends on its chemical structure, the presence of guaiacyl ( $\mathrm{G}$ monomer) and/or syringyl ( $\mathrm{S}$ monomer) units, the yield of $\beta-\mathrm{O}-4$ linkages, the polarity, the acidity of the medium, and the catalytic performance of the catalyst system.

To explain and understand the catalytic performance of the ZVO system in biomass delignification and depolymerization, the elemental composition of the obtained ZVO was examined by energy-dispersive X-ray (EDX) analysis. Figure S3 shows the presence of three elements zinc, oxygen, and vanadium with a $\mathrm{V} / \mathrm{Zn}$ ratio of 0.86 . The surface compositions and chemical states of ZVO before and after catalysis $\left(200{ }^{\circ} \mathrm{C}\right)$ were studied by X-ray photoelectron spectroscopy. The survey spectrum (Figure 9a) illustrates the correct chemical composition of the as-prepared ZVO, apart from the $\mathrm{C} 1 \mathrm{~s}$ signal peak that appeared at ca. $284.78 \mathrm{eV}$ corresponding to impurities formed during the analysis or the carbone formed upon calcination. The peaks of the three constituent elements of $\mathrm{ZVO}$, such as $\mathrm{Zn}\left(\mathrm{Zn} 2 \mathrm{p}_{3 / 2}\right), \mathrm{V}\left(\mathrm{V} \mathrm{2} \mathrm{p}_{3 / 2}\right)$, and $\mathrm{O}(\mathrm{O} 1 \mathrm{~s})$, appeared, respectively, at $1021.37,517.04$, and $530.16 \mathrm{eV}$. Figure $9 \mathrm{~b}$ shows the high-resolution $\mathrm{Zn} 2 \mathrm{p}$ spectrum. Thus, the two binding energies at about 1021.37 and $1043.9 \mathrm{eV}$ could be fairly attributed to $\mathrm{Zn} 2 \mathrm{p}_{3 / 2}$ and $\mathrm{Zn} 2 \mathrm{p}_{1 / 2}$ of $\mathrm{Zn}^{2+}$, 
respectively. ${ }^{46}$ The highest binding energy peaks located at approximately 524.8 and $517.5 \mathrm{eV}$ (Figure 9c) are the result of $\mathrm{V} 2 \mathrm{p}_{1 / 2}$ and $\mathrm{V} 2 \mathrm{p}_{3 / 2}$, respectively. These satellite peaks are characteristic of the presence of $\mathrm{V}^{5+}$ ions. ${ }^{47}$ In addition, the $\mathrm{O}$ 1s core-level peak from the lattice oxygen in ZVO was detected at ca. $530.1 \mathrm{eV}$ (Figure 9c). However, it is highly probable that there is an electronic dynamic exchange between zinc and vanadium, which leads to the exceptional catalytic performance of ZVO.

The possibility to reuse the catalyst was also studied successfully, and ZVO retained its catalytic performance (Table 5). To obtain information on the stability of the catalyst as well as its catalytic activity, this nanostructured mixed oxide was recycled under conditions similar to those used for the delignification/depolymerization $\left(200{ }^{\circ} \mathrm{C}, 100\right.$ $\mathrm{kPa}, 4 \mathrm{~h}$ ). The catalyst was recovered after reaction (see the Experimental Section), washed, and dried at $100{ }^{\circ} \mathrm{C}$ for $24 \mathrm{~h}$. It was tested in a new experiment, under the same conditions (Table 5). However, some conclusions were inferred from these tests: (i) a small decrease in the delignification degree was observed with the recovered $\mathrm{ZVO}$ in comparison with the freshly prepared ZVO; (ii) also, a small decrease in lignin conversion was observed with 68 and $62 \%$, respectively, for run \#2 and run \#3, while freshly prepared ZVO showed $78 \%$ conversion; and (iii) no effect was observed on the reaction selectivity by using recovered ZVO (Table 5).

To understand this phenomenon, we also analyzed the recovered ZVO by XRD and SEM. From a mechanical stability point of view, the structure of $\mathrm{ZVO}$ is unchangeable, according to XRD and SEM analyses (Figures S4 and S5), which will inevitably eliminate the fouling theory of ZVO. XPS characterization of the recovered $\mathrm{ZVO}$ reveals that the three constituent elements of ZVO retain their degrees of oxidation, which explains the retention of an almost stable catalytic activity of ZVO.

\section{CONCLUSIONS}

In summary, a novel nanostructured catalyst based on zinc vanadate mixed oxide (ZVO) was successfully synthesized via a co-precipitation process followed by heat treatment. Indeed, we have shown that ZVO is an oxide with exceptional catalytic performance and with an interesting selectivity for oxidative depolymerization of biomass. Poplar wood biomass was converted via this catalytic process into highly value-added chemicals and polymers. The influence of some reaction conditions was examined. The highest conversion of lignin, cellulose, and hemicellulose depolymerization was achieved at $200{ }^{\circ} \mathrm{C}$ for $4 \mathrm{~h}$. Oligosaccharides and aromatic and furan compounds were obtained as the major components. This gives rise to new performing catalysts for the cutting-edge biorefinery industry.

\section{EXPERIMENTAL SECTION}

Synthesis of ZVO. An aqueous solution of $\mathrm{Zn}\left(\mathrm{NO}_{3}\right)_{2}(0.1$ M) was mixed with a $0.1 \mathrm{M}$ aqueous solution of $\mathrm{NH}_{4} \mathrm{VO}_{3}$ in a beaker at room temperature. A concentrated solution of $\mathrm{NH}_{4} \mathrm{OH}$ was added dropwise to adjust the $\mathrm{pH}$ to 10 , and then the mixture was stirred and heated at $80{ }^{\circ} \mathrm{C}$ for $4 \mathrm{~h}$ on a hot plate. The white precipitate was filtered, washed with deionized water, and then dried in an oven at $60{ }^{\circ} \mathrm{C}$ for $12 \mathrm{~h}$. The obtained powder was further heated in a muffle furnace at 550 ${ }^{\circ} \mathrm{C}$ with a ramp rate of $5{ }^{\circ} \mathrm{C} / \mathrm{min}$ for $4 \mathrm{~h}$.
General Procedure for the Catalytic Depolymerization of Biomass. The poplar wood biomass used in this study was ground using knife-milling (Retsch SM 100, Germany) with a screening size of $1 \mathrm{~mm}$. The experiments were developed using a $50 \mathrm{~mL}$ stirred batch reactor (Parr 5000). The treatments of all samples were carried out in deionized water at 160,180 , and $200{ }^{\circ} \mathrm{C}$ with $10 \% \mathrm{O}_{2}$ in $90 \%$ of $\mathrm{N}_{2}$ for 4 $\mathrm{h}$ of reaction. The reactions were catalyzed using $80 \mathrm{mg}$ of ZVO for $400 \mathrm{mg}$ of poplar wood biomass dispersed in $10 \mathrm{~mL}$ of deionized water. The concentration of wood in the reactor was $40 \mathrm{~g} / \mathrm{L}$. These conditions were chosen from previous experiments. ${ }^{48}$ After the completion of the reaction, the catalyst was separated from the reaction mixture by decantation (due to the low density of ZVO) followed by filtration on fine filters. We note that it was difficult to recover the entire quantity of the catalyst from the solid residue. The reaction mixture was then centrifuged ( $20 \mathrm{~min}, 4000 \mathrm{tr} / \mathrm{min}$ ), and the residue was separated from the liquid phase (Scheme 2), washed with water, and dried at room temperature. The final volume of the liquid product (WSol) was obtained by combining the liquid phase and washing water. The WSol fraction (Scheme 2$)$ was treated with dichloromethane $(4 \times 30$ $\mathrm{mL}$ ) to extract the lower-molecular-weight products such as phenolic compounds and furans obtained from the lignin and carbohydrate depolymerization. The organic layer $(\mathrm{DiCl})$ was dried over $\mathrm{MgSO}_{4}$ and evaporated under reduced pressure. The residues were dissolved in $1 \mathrm{~mL}$ of dichloromethane in the presence of an internal standard for GC-MS analysis as described below. The rest of the water-soluble fraction (WSol, Scheme 2) was concentrated and analyzed by HPLC and GPC to quantify the mono- and oligosaccharides and organic acids.

The selectivity of the obtained products was calculated using the following equations:

$$
\begin{aligned}
\% \text { conversion }= & \frac{[\text { initial mass }- \text { mass after reaction }]}{[\text { initial mass }]} \\
& \times 100
\end{aligned}
$$

$$
\begin{aligned}
\% \text { yield }= & \frac{[(\text { number of carbons } \times \text { mass }) \text { product }]}{[(\text { number of carbons } \times \text { mass }) \text { substrate }]} \\
& \times 100
\end{aligned}
$$

$$
\% \text { selectivity }=\frac{\text { yield }}{\text { conversion }} \times 100
$$

The recovered catalyst was washed twice with dichloromethane and water and dried at $100{ }^{\circ} \mathrm{C}$ for $24 \mathrm{~h}$ before being reused in subsequent reactions to demonstrate its prolonged activity.

Materials and Apparatus. Metallic salts, reagents, and solvents were purchased from Sigma-Aldrich and used without further purification. X-ray diffraction (XRD) patterns were obtained at room temperature on a Bruker AXS D-8 diffractometer using $\mathrm{Cu} \mathrm{K} \alpha$ radiation in the Bragg-Brentano geometry $(\theta-2 \theta)$. Scanning electron microscopy (SEM) pictures were recorded on a FEI Quanta 200 microscope after carbon metallization. Transmission electron microscopy (TEM) was conducted with a Tecnai G2 microscope at 120 $\mathrm{kV}$. Gas adsorption data in $\mathrm{N}_{2}$ were collected using a Quantachrome Autosorb-1 automatic analyzer. Prior to $\mathrm{N}_{2}$ sorption, all samples were degassed at $100{ }^{\circ} \mathrm{C}$ overnight under dynamic vacuum conditions. 
Specific surface areas were determined from the nitrogen adsorption/desorption isotherms at $77 \mathrm{~K}$ using the BrunauerEmmett-Teller (BET) method.

X-ray photoelectron spectroscopy (XPS) studies were carried out in an ESCALAB 250 Thermo Electron spectrometer equipped with a monochromatic $\mathrm{Al} \mathrm{K} \alpha \mathrm{X}$-ray source $(h \nu=1486.6 \mathrm{eV})$.

The composition of the solid sample was determined using strong-acid hydrolysis of the carbohydrates. The lignin content in samples was determined by the Klason and Bromure acetyl methods. Dried samples of $100 \mathrm{mg}$ were treated with $72 \%$ $\mathrm{H}_{2} \mathrm{SO}_{4}$ at ambient temperature for $1 \mathrm{~h}$. The solutions were diluted with water to $12 \% \mathrm{H}_{2} \mathrm{SO}_{4}$ and autoclaved at $100{ }^{\circ} \mathrm{C}$ for $1 \mathrm{~h}$. The hydrolysates were centrifuged at $10000 \mathrm{rpm}$ for 10 min. The Klason lignin content was determined as the weight of the residue.

The supernatant was analyzed for sugars by high-pressure liquid chromatography (HPLC). HPLC analysis was used to quantify the acetic acid, monosaccharides, furfural, and hydroxymethylfurfural (HMF). The analysis was performed with a Water system, using a BioRad HPX87H column at 60 ${ }^{\circ} \mathrm{C}$ (Bio-Rad Laboratories). The solvent was $0.005 \mathrm{M} \mathrm{H}_{2} \mathrm{SO}_{4}$ and the flow rate $0.5 \mathrm{~mL} / \mathrm{min}$. The recovery of monosaccharides, furans, and organic acids was determined by standard addition (D-fucose) to the samples. An ultraviolet diode-array detector and a refractive index (RI) detector were connected in series. The UV detector was used to quantify phenols, furfural, and HMF in the samples, while the RI detector was used to quantify carbohydrates. The system was calibrated with glucose, xylose, arabinose, organic acids, furfural, and HMF standards (Sigma-Aldrich). Before measurements, all of the samples $(2 \mathrm{~mL})$ were filtered through $0.22 \mu \mathrm{m}$ filters.

The liquid fraction (WSol) consisted of both oligomers and monomers resulting from the catalytic degradation of lignin and polysaccharides. Phenolic and furan compounds isolated from the liquid fraction (WSol) by liquid-phase extraction with dichloromethane $(\mathrm{DiCl})$ were identified and quantified using a GC-MS system equipped with a $30 \mathrm{~m} \times 0.25 \mathrm{~mm} \times 0.25 \mu \mathrm{m}$ SLP-5MS column. The GC-MS analysis was carried out with decosane as an internal standard using Thermo scientific GC/ MS-2010. Helium gas was employed as a carrier gas at a constant flow rate of $1 \mathrm{~mL} / \mathrm{min}$. The heating of the column started at $80{ }^{\circ} \mathrm{C}$, and was programmed to $250{ }^{\circ} \mathrm{C}$ at a rate of $10{ }^{\circ} \mathrm{C} / \mathrm{min}$ and held for $10 \mathrm{~min}$. The compounds obtained were grouped as aldehydes, acids, ketones, phenols, and polyaromatic hydrocarbons. A sample of the water-soluble fraction (WSol) was analyzed by HPLC directly to quantify the free monosaccharides, organic acids, furfural, and HMF.

Gel permeation chromatography (GPC) was used to measure the molar mass distributions of oligomers in WSol samples. In all of the cases, a sample of $1.2 \mathrm{~mL}$ of the filtered liquid was mixed with $0.2 \mathrm{~mL}$ of a solution of $0.35 \mathrm{M} \mathrm{NaNO}_{3}$, containing $0.02 \% \mathrm{NaN}_{3}$. The GPC analysis was performed with a Shodex SB 801-804 column in series at $40{ }^{\circ} \mathrm{C}$ using $0.05 \mathrm{M} \mathrm{NaNO}_{3}$, containing $83 \mathrm{mg} / \mathrm{L} \mathrm{NaN}_{3}$, as the solvent at a flow rate of $0.4 \mathrm{~mL} / \mathrm{min}$. The system was calibrated with narrow standards of pullulan.

Oligosaccharides in the WSol fraction were quantified using HPLC. The WSol sample was hydrolyzed using $12 \% \mathrm{H}_{2} \mathrm{SO}_{4}$ at $100{ }^{\circ} \mathrm{C}$ for $1 \mathrm{~h}$ to convert oligomers to their constitutive monomers and analyzed by HPLC to quantify the total content of oligomers in the sample. The lignin associated with the oligosaccharides was measured as acid-soluble lignin and was estimated from the absorbance of the solution between 260 and $280 \mathrm{~nm}$. All analyses were performed in triplicate. ${ }^{50-54}$

Lignin polymers were degraded by thioacidolysis to estimate the $\mathrm{G} / \mathrm{S} / \mathrm{H}$ ratio and the content of $\beta-\mathrm{O}-4$ linked structures according to Lapierre's procedure. ${ }^{26,49}$ The main degradation products were analyzed by GC as TMSi derivatives using a J\&W Scientific column (DB 1, $30 \mathrm{~m}, 0.25 \mathrm{~mm}, 0.25 \mu \mathrm{m}$ film), a flame ionization detector (FID), and tetracosane as the internal standard.

FTIR spectroscopy was performed on $2 \mathrm{mg}$ of the dry sample carefully mixed with $100 \mathrm{mg}$ of dry $\mathrm{KBr}$ and pressed into a self-supporting pellet. FTIR measurements were performed using a Bruker Tensor 27 infrared spectrometer. For each sample, 32 spectra were accumulated between 4000 and $400 \mathrm{~cm}^{-1}$ and averaged. The resulting spectra were normalized to the highest peak in the fingerprint region between 2000 and $800 \mathrm{~cm}^{-1}$.

\section{ASSOCIATED CONTENT}

Supporting Information

The Supporting Information is available free of charge at https://pubs.acs.org/doi/10.1021/acsomega.9b02159.

Nitrogen adsorption/desorption isotherms of ZVO; ratios of the intensity of the lignin-associated band with carbohydrates; EDX spectrum of ZVO; XRD pattern of the recovered catalyst without any treatment; SEM images of the recovered ZVO after reaction; survey XPS spectrum of ZVO after reaction; elemental composition of the ZVO sample obtained by XPS; and comparison of yields of products obtained by biomass conversion over various heterogeneous catalysts (PDF)

\section{AUTHOR INFORMATION}

\section{Corresponding Author}

*E-mail: abdellatif.barakat@inra.fr.

ORCID

Eric Dubreucq: 0000-0002-8904-504X

Abdellatif Barakat: 0000-0003-4196-4351

Notes

The authors declare no competing financial interest.

\section{ACKNOWLEDGMENTS}

This work was sponsored by INRAE-SupAgro at Montpellier in France and also by Mohammed VI Polytechnic University (UM6P) at Benguerir in Morocco. We thank the technical support of the LipPolGreen platform of UMR IATE at Montpellier for their support and also Dr. Valerie FLAUD for his assistance to achieve XPS analyses.

\section{REFERENCES}

(1) Aho, A.; Kumar, N.; Eränen, K.; Salmi, T.; Hupa, M.; Murzin, D. Y. Catalytic Pyrolysis of Woody Biomass in a Fluidized Bed Reactor: Influence of the Zeolite Structure. Fuel 2008, 87, 2493-2501.

(2) Zheng, J.-l.; Yi, W.-m.; Wang, N.-n. Bio-Oil Production from Cotton Stalk. Energy Convers. Manage. 2008, 49, 1724-1730.

(3) Laureano-Perez, L.; Teymouri, F.; Alizadeh, H.; Dale, B. E. Understanding Factors That Limit Enzymatic Hydrolysis of Biomass. Appl. Biochem. Biotechnol. 2005, 124, 1081-1100.

(4) Salmén, L.; Olsson, A. M. Interaction between Hemicelluloses, Lignin and Cellulose: Structure-Property Relationships. J. Pulp Pap. Sci. 1998, 24, 99-103. 
(5) Monties, B.; Fukushima, K. Occurrence, Function and Biosynthesis of Lignins. Biopolymers 2001, 1, 1-64.

(6) Gamelas, J. A. F.; Gaspar, A. R.; Evtuguin, D. V.; Neto, C. P. Transition Metal Substituted Polyoxotungstates for the Oxygen Delignification of Kraft Pulp. Appl. Catal., A 2005, 295, 134-141.

(7) Evtuguin, D. V.; Pascoal Neto, C.; Rocha, J.; Pedrosa de Jesus, J. D. R. Oxidative Delignification in the Presence of Molybdovanadophosphate Heteropolyanions: mechanism and Kinetic Studies. Appl. Catal., A 1998, 167, 123-139.

(8) Pan, X.; Kadila, J. F.; Ehara, K.; Gilkes, N.; Saddler, J. N. Organosolv Ethanol Lignin from Hybrid Poplar as a Radical Scavenger: Relationship between Lignin Structure, Extraction Conditions, and Antioxidant Activity. J. Agric. Food Chem. 2006, 54, 5806-5813.

(9) Sambusiti, C.; Licari, A.; Solhy, A.; Aboulkas, A.; Cacciaguerra, T.; Barakat, A. One-Pot Dry Chemo-Mechanical Deconstruction for Bioethanol Production from Sugarcane Bagasse. Bioresour. Technol. 2015, 181, 200-206.

(10) Gamelas, J. A. F.; Pontes, A. S. N.; Evtuguin, D. V.; Xavier, A. M. R. B.; Esculcas, A. P. New Polyoxometalate - Laccase Integrated System for Kraft Pulp Delignification. Biochem. Eng. J. 2007, 33, 141147.

(11) Mosier, N.; Wyman, C.; Dale, B.; Elander, R.; Lee, Y. Y.; Holtzapple, M.; Ladisch, M. Features of Promising Technologies for Pretreatment of Lignocellulosic Biomass. Bioresour. Technol. 2005, 96, 673-686.

(12) Tavares, A. P. M.; Gamelas, J. A. F.; Gaspar, A. R.; Evtuguin, D. V.; Xavier, A. M. R. B. A Novel Approach for the Oxidative Catalysis Employing Polyoxometalate - Laccase System: Application to the Oxygen Bleaching of Kraft Pulp. Catal. Commun. 2004, 5, 485-489.

(13) Gaspar, A. R.; Gamelas, A. F.; Evtuguin, V.; Pascoal, C. Alternatives for Lignocellulosic Pulp Delignification Using Polyoxometalates and Oxygen: A Review. Green Chem. 2007, 9, 717-730.

(14) Wang, F.; Dubois, J.; Ueda, W. Catalytic Performance of Vanadium Pyrophosphate Oxides (VPO) in the Oxidative Dehydration of Glycerol. Appl. Catal., A 2010, 376, 25-32.

(15) Yin, Z.; Xiao, Y.; Wang, X.; Wang, W.; Zhao, D.; Cao, M. MoV2O8 Nanostructures: Controlled Synthesis and Lithium Storage Mechanism. Nanoscale 2016, 8, 508-516.

(16) Hu, Q.; Liao, J.-Y.; Zou, B.-K.; Wang, H.-Y.; Chen, C.-H. InSitu Catalytic Formation of Graphene Decoration on Na3V2(PO4)3 Particles for Ultrafast and Long-Life Sodium Storage. J. Mater. Chem. A 2016, 4, 16801-16804.

(17) Li, Q.; Zhao, Y.; Kuang, Q.; Fan, Q.; Dong, Y.; Liu, X. Superstructure ZrV2O7 Nanofibres: Thermal Expansion, Electronic and Lithium Storage Properties. Phys. Chem. Chem. Phys. 2016, 18, 32160-32168.

(18) Hernández, S.; Thalluri, S. M.; Sacco, A.; Bensaid, S.; Saracco, G.; Russo, N. Photo-Catalytic Activity of BiVO4 Thin-Film Electrodes for Solar-Driven Water Splitting. Appl. Catal., A 2015, 504, 266-271.

(19) Gan, L.-H.; Deng, D.; Zhang, Y.; Li, G.; Wang, X.; Jiang, L.; Wang, C.-R. Zn3V2O8 Hexagon Nanosheets: A High-Performance Anode Material for Lithium-Ion Batteries. J. Mater. Chem. A 2014, 7, 2461-2466.

(20) Li, T.; Luo, J.; Honda, Z.; Fukuda, T.; Kamata, N. Sintering Condition and Optical Properties of Zn3V2O8 Phosphor. Adv. Mater. Phys. Chem. 2012, 02, 173-177.

(21) Mondal, C.; Ganguly, M.; Sinha, A. K.; Pal, J.; Sahoo, R.; Pal, T. Robust Cubooctahedron Zn3V2O8 in Gram Quantity: A Material for Photocatalytic Dye Degradation in Water. CrystEngComm 2013, 15, 6745-6751.

(22) Mazloom, F.; Masjedi-arani, M.; Salavati-niasari, M. Rapid and Solvent-Free Solid-State Synthesis and Characterization of Zn3V2O8 Nanostructures and Their Phenol Red Aqueous Solution Photodegradation. Solid State Sci. 2017, 70, 101-109.

(23) Xiao, L.; Zhao, Y.; Yin, J.; Zhang, L. Clewlike ZnV2O4 Hollow Spheres: Nonaqueous Sol-Gel Synthesis, Formation Mechanism, and Lithium Storage Properties. Chem. - Eur. J. 2009, 15, 9442-9450.
(24) Mazloom, F.; Masjedi-arani, M.; Ghiyasiyan-arani, M.; Salavatiniasari, M. Novel Sodium Dodecyl Sulfate-Assisted Synthesis of Zn 3 V 2 O 8 Nanostructures via a Simple Route. J. Mol. Liq. 2016, 214, $46-53$.

(25) Jacquet, G.; Pollet, B.; Lapierre, C.; Francesch, C.; Rolando, C.; Faix, O. Thioacidolysis of enzymatic dehydrogenation polymers from p-hydroxyphenyl, guaiacyl, and syringyl precursors. Holzforschung 1997, 51, 349-354.

(26) Kruse, A.; Meier, D.; Rimbrecht, P.; Schacht, M. Gasification of Pyrocatechol in Supercritical Water in the Presence of Potassium Hydroxide. Ind. Eng. Chem. Res. 2000, 39, 4842-4848.

(27) Santos, R. B.; Hart, P.; Jameel, H.; Chang, H.-m. Wood Based Lignin Reactions Important to the Biorefinery and Pulp and Paper Industries. BioResources 2013, 8, 1456-1477.

(28) Wang, P.; Fu, Y.; Shao, Z.; Zhang, F.; Qin, M. Structural Changes to Aspen Wood Lignin during Autohydrolysis Pretreatment. BioResources 2016, 11, 4086-4103.

(29) Feghali, E.; Carrot, G.; Thuéry, P.; Genre, C.; Cantat, T. Convergent Reductive Depolymerization of Wood Lignin to Isolated Phenol Derivatives by Metal-Free Catalytic Hydrosilylation. Energy Environ. Sci. 2015, 8, 2734-2743.

(30) Garrote, E.; Capote, R.; Pedrosa, R. Single-particle calculations in an axially deformed Woods-Saxon potential with Cassinian ovals parametrization of the shape deformation. Comput. Phys. Commun. 1995, 92, 267-276.

(31) Conner, A. H.; River, B. H.; Lorentz, L. F. Carbohydrates modified phenol-foemadehyde resins. J. Wood Chem. Technol. 1986, 6, 591-613.

(32) Liu, C.; Wyman, C. E. The Effect of Flow Rate of Compressed Hot Water on Xylan, Lignin, and Total Mass Removal from Corn Stover. Ind. Eng. Chem. Res. 2003, 42, 5409-5416.

(33) Feng, J.; He, Y.; Liu, Y.; Du, Y.; Li, D. Supported Catalysts Based on Layered Double Hydroxides for Catalytic Oxidation and Hydrogenation. Chem. Soc. Rev. 2015, 44, 5291-5319.

(34) De, S.; Dutta, S.; Saha, B. Critical Design of Heterogeneous Catalysts for Biomass Valorization: Current Thrust and Emerging Prospects. Catal.: Sci. Technol. 2016, 6, 7364-7385.

(35) Song, J.; Fan, H.; Ma, J.; Han, B. Conversion of Glucose and Cellulose into Value-Added Products in Water and Ionic Liquids. Green Chem. 2013, 15, 2619-2635.

(36) Tong, X.; Ma, Y.; Li, Y. Biomass into Chemicals: Conversion of Sugars to Furan Derivatives by Catalytic Processes. Appl. Catal., A 2010, 385, 1-13.

(37) Wang, T.; Glasper, J. A.; Shanks, B. H. Kinetics of Glucose Dehydration Catalyzed by Homogeneous Lewis Acidic Metal Salts in Water. Appl. Catal., A 2015, 498, 214-221.

(38) Liu, C.; Huamin, W.; Ayman M, K.; Junming, S.; Yong, W. Catalytic Fast Pyrolysis of Lignocellulosic Biomass. Chem. Soc. Rev. 2014, 43, 7594-7623.

(39) Li, J.; Henriksson, G.; Gellerstedt, G. Lignin Depolymerization/ repolymerization and Its Critical Role for Delignification of Aspen Wood by Steam Explosion. Bioresour. Technol. 2007, 98, 3061-3068.

(40) Erdtman, H. Lignins: Occurrence, formation, structure and reactions, K. V. Sarkanen and C. H. Ludwig, Eds., John Wiley \& Sons, Inc., New York, 1971. 916 pp. \$35.00. J. Polym. Sci., Part B: Polym. Lett. 1972, 228-230.

(41) Faix, O. Classification of Lignins from Different Botanical Origins by FT-IR Spectroscopy. Holzforschung 1991, 45, 21-28.

(42) Rodrigues, J.; Faix, O.; Pereira, H. Determination of Lignin Content of Eucalyptus Glotylus Wood Using FTIR Spectroscopy. Holzforschung 1998, 52, 46-50.

(43) Reddy, A. S.; Gopinath, C. S.; Chilukuri, S. Selective OrthoMethylation of Phenol with Methanol over Copper Manganese Mixed-Oxide Spinel Catalysts. J. Catal. 2006, 243, 278-291.

(44) Cheng, F.; Sun, J.; Wang, Z.; Zhao, X.; Hu, Y. Organosolv fractionation and simultaneous conversion of lignocellulosic biomass in aqueous 1,4 butanediol/acidic ionic-liquids solution. Ind. Crops Prod. 2019, 138, No. 111573. 
(45) Yuan, Z.; Wen, Y.; Kapu, N. S.; Beatson, R.; Martinez, M. A biorefinery scheme to fractionate bamboo into high-grade dissolving pulp and ethanol. Biotechnol. Biofuels 2017, 10, No. 38.

(46) Yin, Z.; Xiao, Y.; Wang, X.; Wang, W.; Zhao, D.; Cao, M. MoV2O8 nanostructures: controlled synthesis and lithium storage mechanism. Nanoscale 2015, 8, 508-516.

(47) Shahid, M.; Liu, J.; Ali, Z.; Shakir, I.; Farooq, M. Structural and Electrochemical Properties of Single Crystalline MoV2O8 Nanowires for Energy Storage Devices. J. Power Sources 2013, 230, 277-281.

(48) Hdidou, L.; Khallouk, K.; Solhy, A.; Manoun, B.; Oukaroum, A.; Barakat, A. Synthesis of CoFeO Mixed Oxide via Alginate Gelation Process as an Efficient Heterogeneous Catalyst for Lignin Depolymerization in Water. Catal.: Sci. Technol. 2018, 8, 5445-5453. (49) Barakat, A.; Putaux, J. L.; Saulnier, L.; Chabbert, B.; Cathala, B. Characterization of arabinoxylan-DHP (dehydrogenation polymers = lignin model compounds) nanoparticles. Biomacromolecules 2007, 8, $1236-1245$.

(50) Azarpira, A.; Ralph, J.; Lu, F. Catalytic alkaline oxidation of lignin and its model compounds: A pathway to aromatic biochemicals. BioEnergy Res. 2014, 7, 78-86.

(51) Voitl, T.; von Rohr, P. R. Oxidation of lignin using aqueous polyoxometalates in the presence of alcohols. ChemSusChem 2008, 1, $763-769$.

(52) Werhan, H.; Mir, J. M.; Voitl, T.; von Rohr, P. R. Acidic oxidation of kraft lignin into aromatic monomers catalyzed by transition metal salts. Holzforschung 2011, 65, 703.

(53) Gu, X.; Kanghua, C.; Ming, H.; Shi, Y.; Li, Z. La-modified SBA$15 / \mathrm{H}_{2} \mathrm{O}_{2}$ systems for the microwave assisted oxidation of organosolv beech wood lignin. Maderas: Cienc. Tecnol. 2012, 14, 31-41.

(54) Deng, W.; Zhang, H.; Wu, X.; Li, R.; Zhang, Q.; Wang, Y. Oxidative conversion of lignin and lignin model compounds catalyzed by $\mathrm{CeO}_{2}$-supported pd nanoparticles. Green Chem. 2015, 17, 50095018. 